\title{
UAS Based Methodology for Measuring Glide Slope Angles of Airport Precision Approach Path Indicators (PAPI)
}

\author{
March 11, 2020 \\ Yi-Chun Lin, Seyyed Meghdad Hasheminasab, John L. Bullock, Deborah \\ Horton, Adam Baxmeyer, Ayman Habib, and Darcy M. Bullock \\ Lyles School of Civil Engineering \\ Purdue University
}




\section{The Research Teâm}

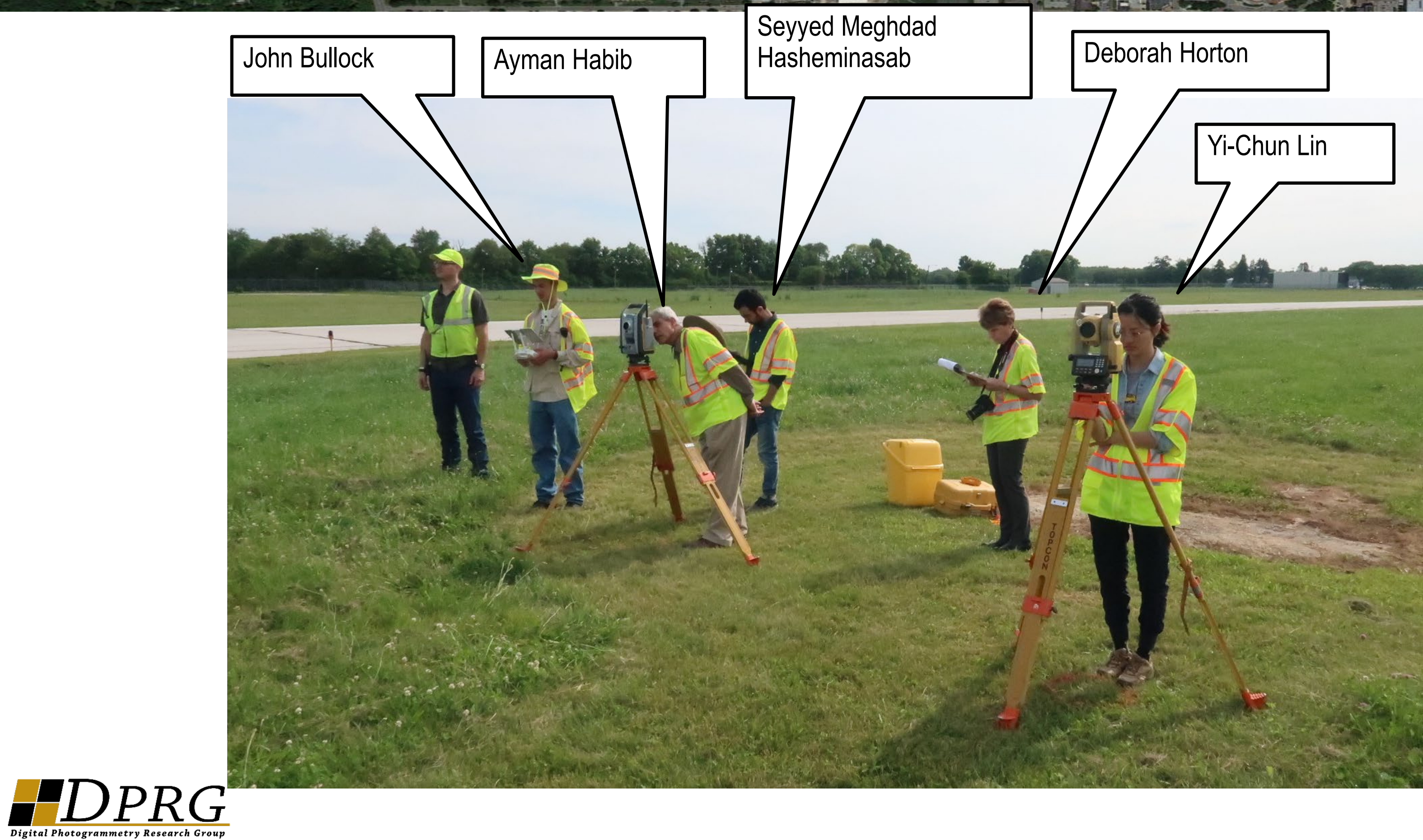




\section{First Author Yi-Chün Line}

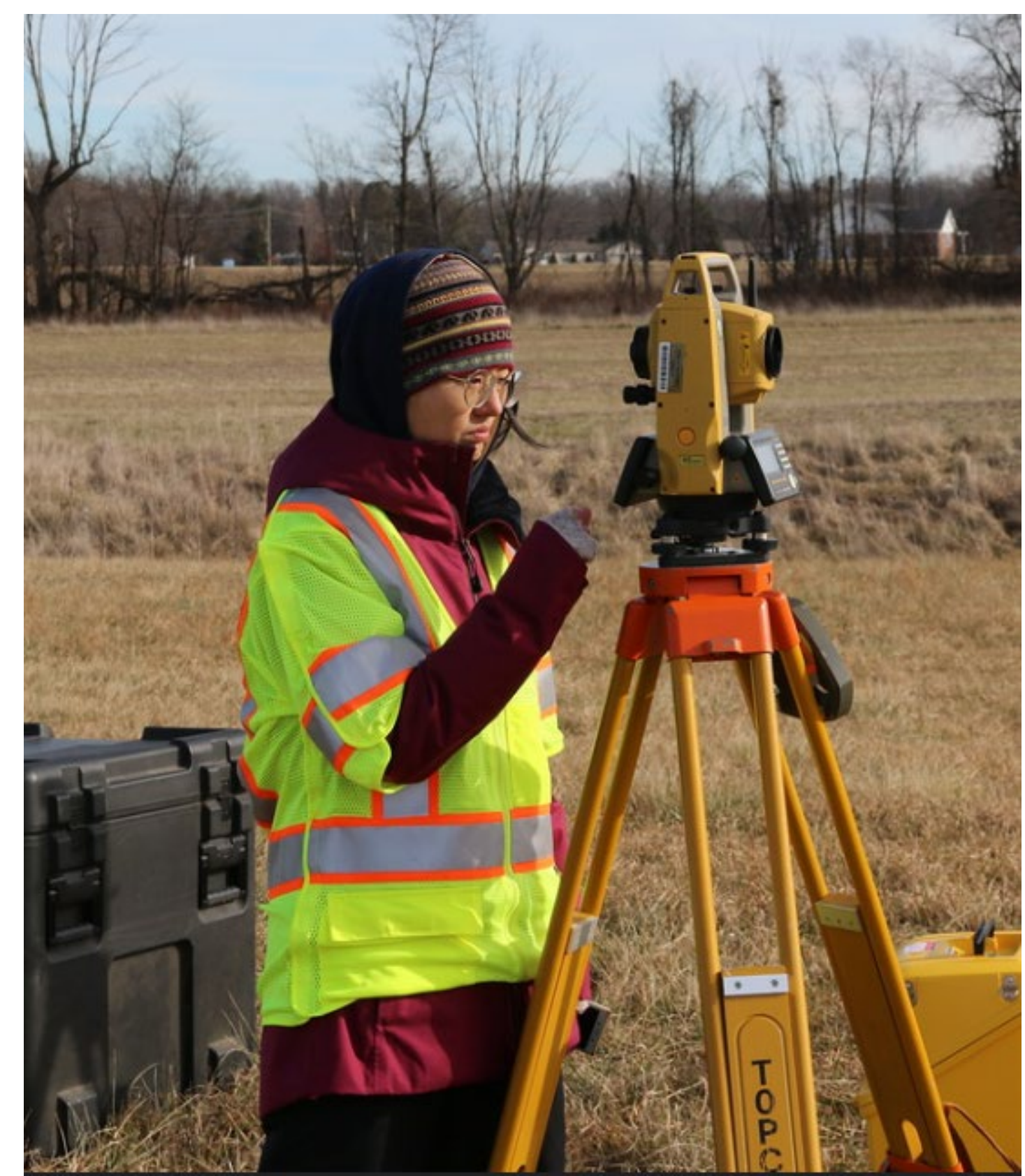




\section{Topics}

1. Research Team

2. Problem Statement

3. PAPI Light Concept

4. PAPI Light Images from Left Seat of Cessna 170

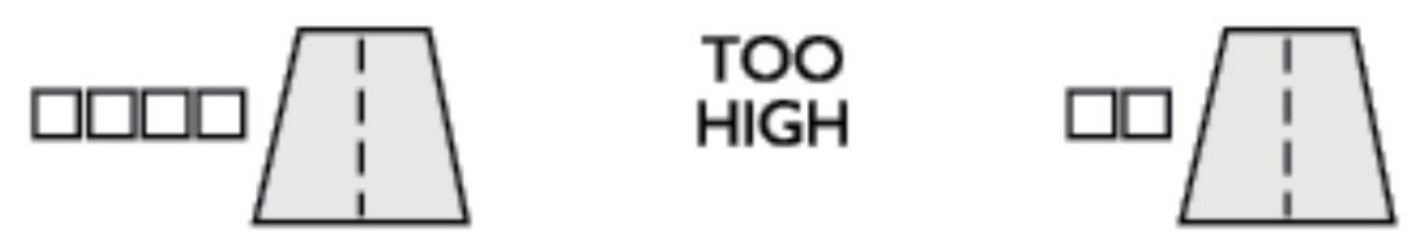

5. Surveying Procedures

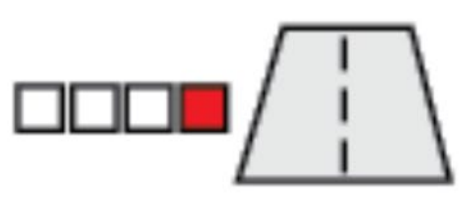

SLIGHTLY $\mathrm{HIGH}$

6. PAPI Light Images from UAS

7. Glideslope Angle Estimate

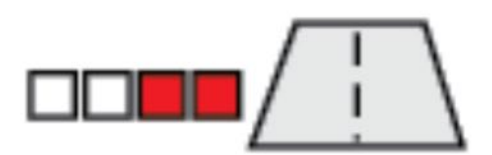

ON CORRECT APPROACH PATH

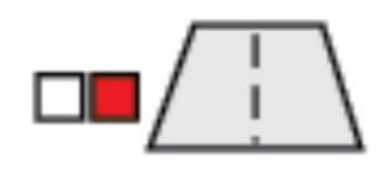

8. Conclusion and Ongoing Implementation Activities

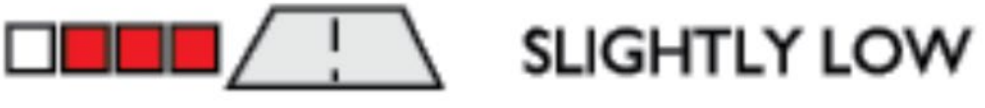




\section{Problem Statement}

- Can we use UAS imagery and high quality positions to evaluate PAPI/APAPI

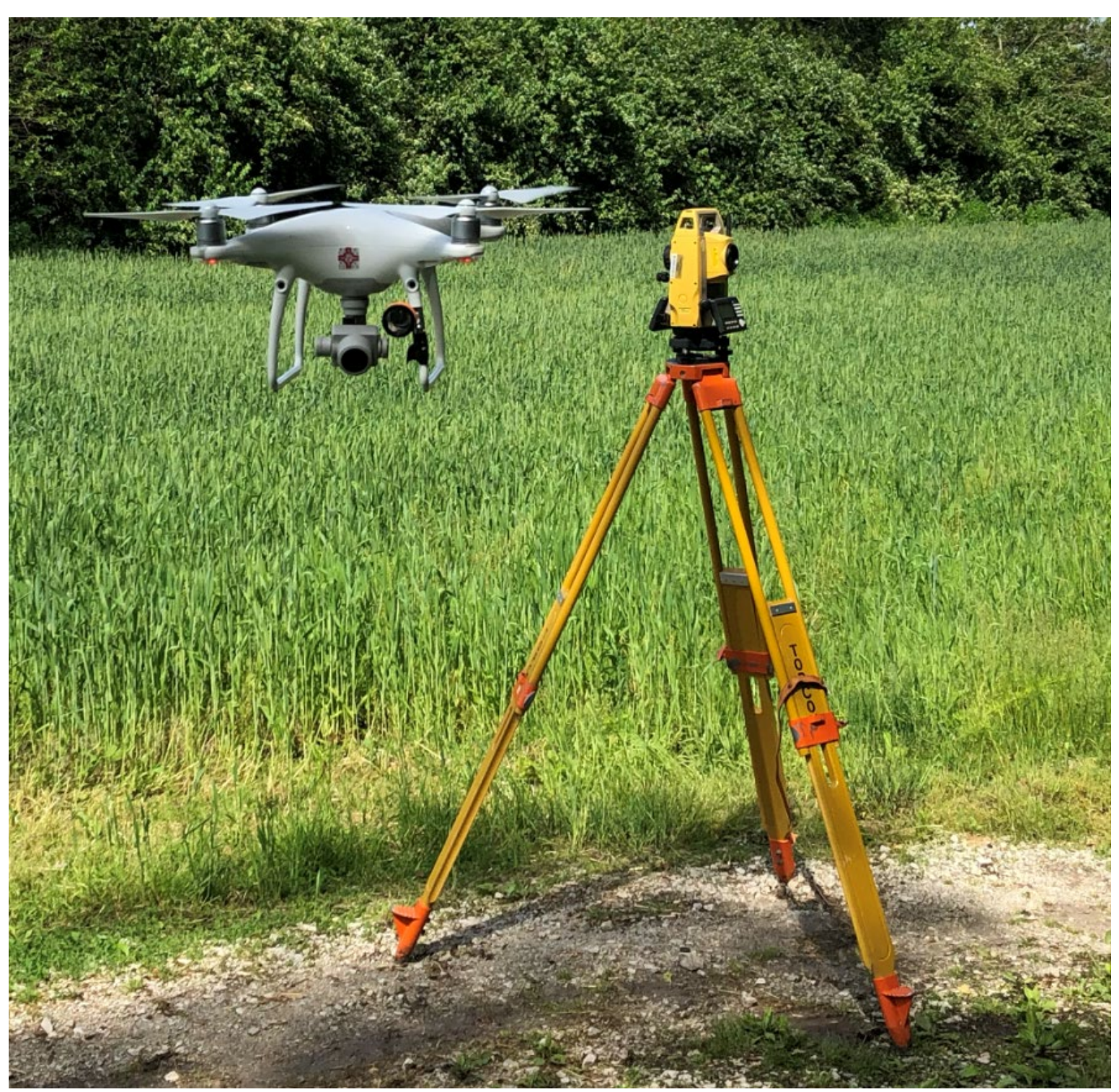

$$
\text { PAPI (PI, P2, P3) }
$$

APAPI (AP)

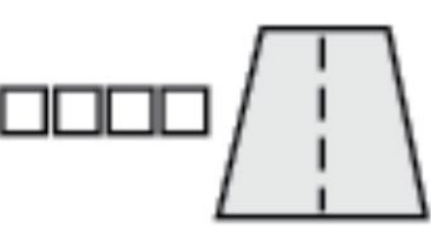

TOO

$\mathrm{HIGH}$
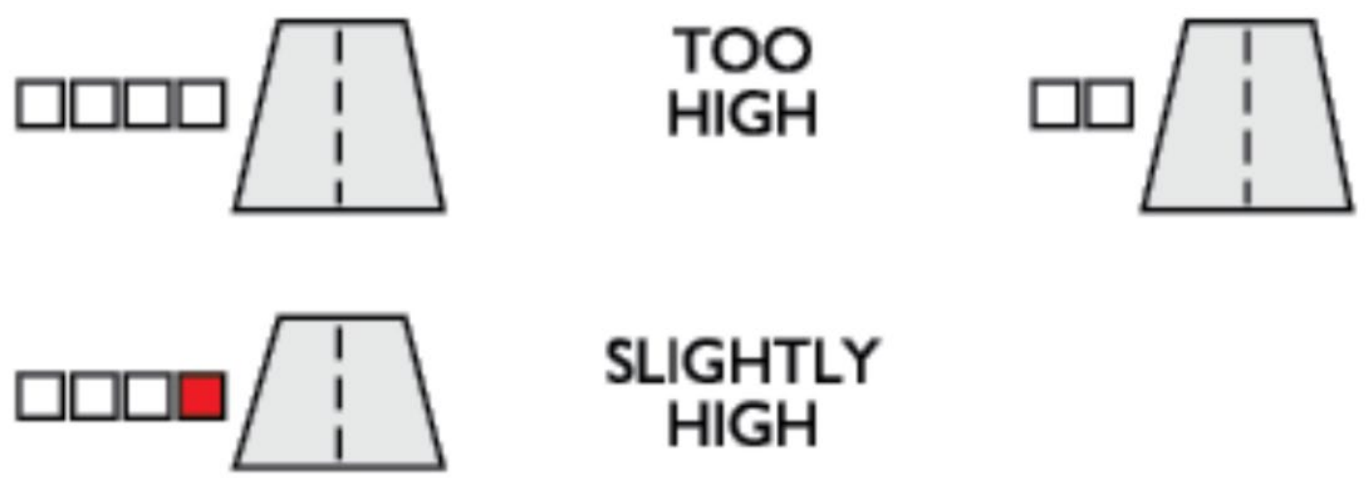

SLIGHTLY $\mathrm{HIGH}$
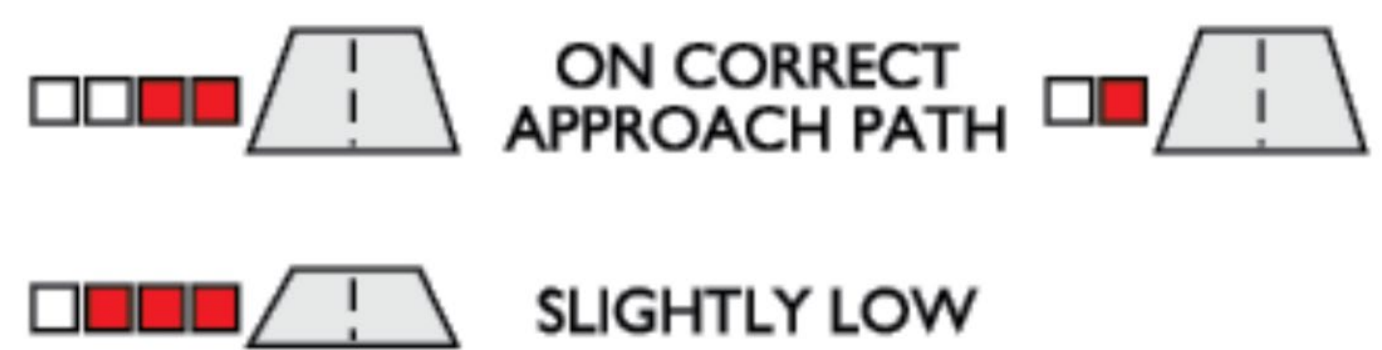

$\square \square \square$ TOO LOW

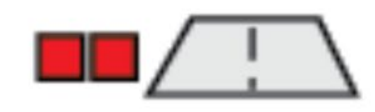




\section{Topics (2)}

1. Research Team

2. Problem Statement

3. PAPI Light Concept

4. PAPI Light Images from Left Seat of Cessna 170

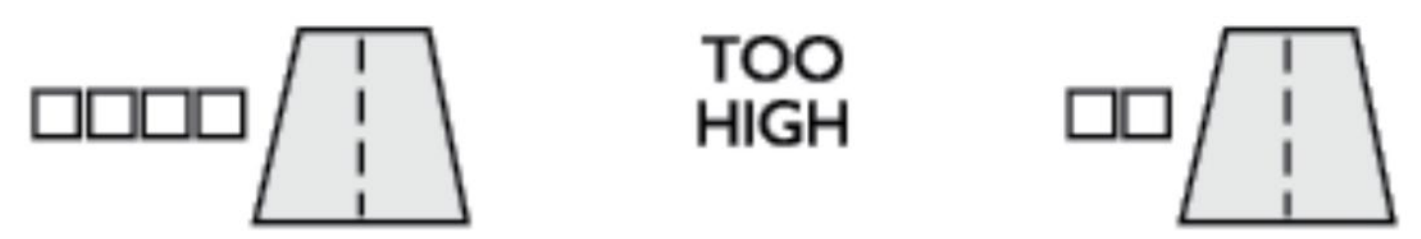

5. Surveying Procedures

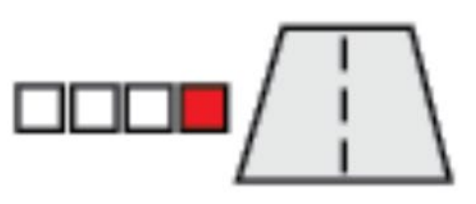

SLIGHTLY $\mathrm{HIGH}$

6. PAPI Light Images from UAS

7. Glideslope Angle Estimate

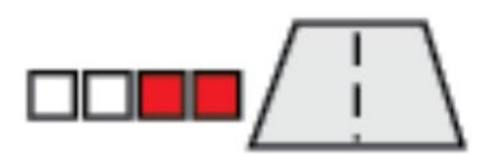

ON CORRECT APPROACH PATH

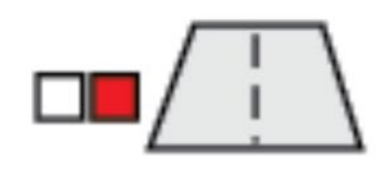

8. Conclusion and Ongoing Implementation Activities

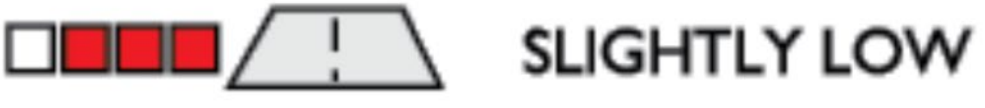




\section{PAPI Light Conceppt}
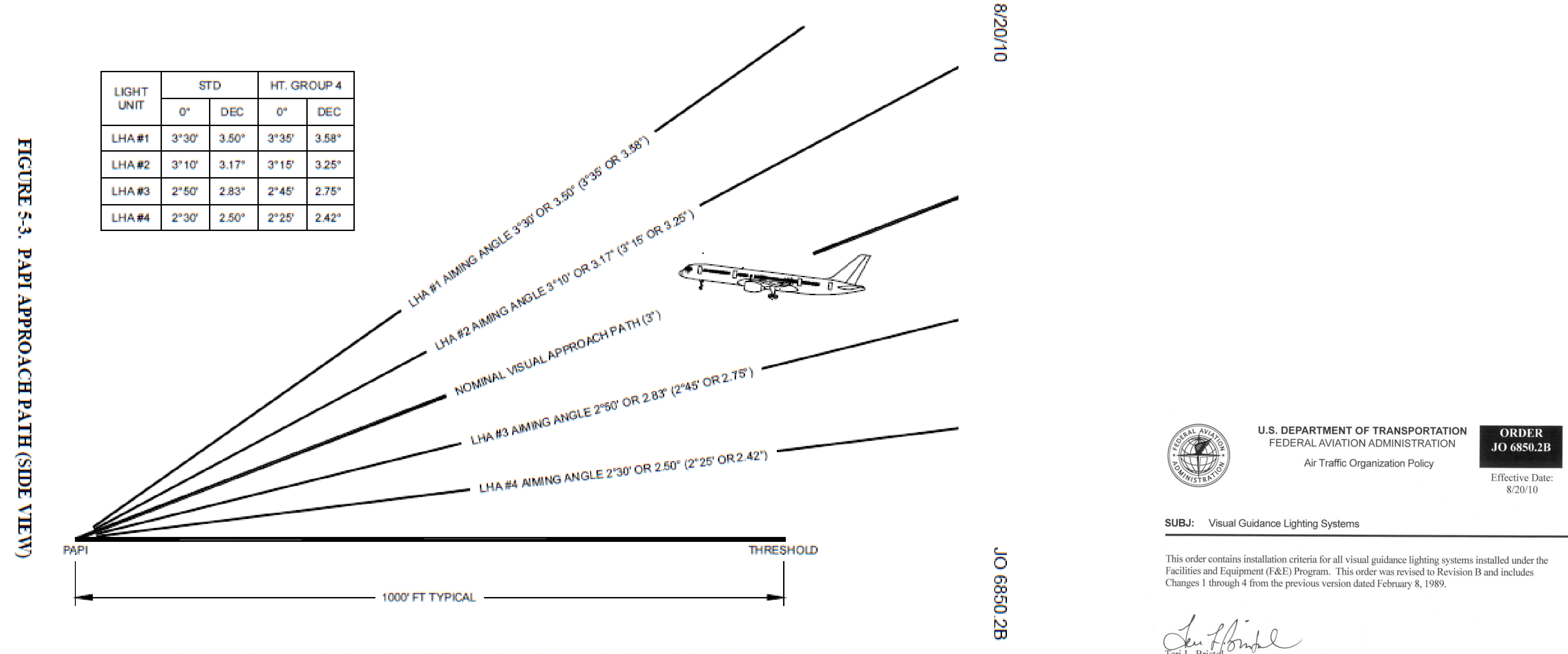

SUBJ: Visual Guidance Lighting Systems

This order contains installation criteria for all visual guidance lighting systems installed under the
Facilities and Equipment ( F\&E) Program. This order was revised to Revision B and includes

Aleufforinge

Vice Presidemt Technical Operations Services 


\section{PAPI Light Concêpt (2)}

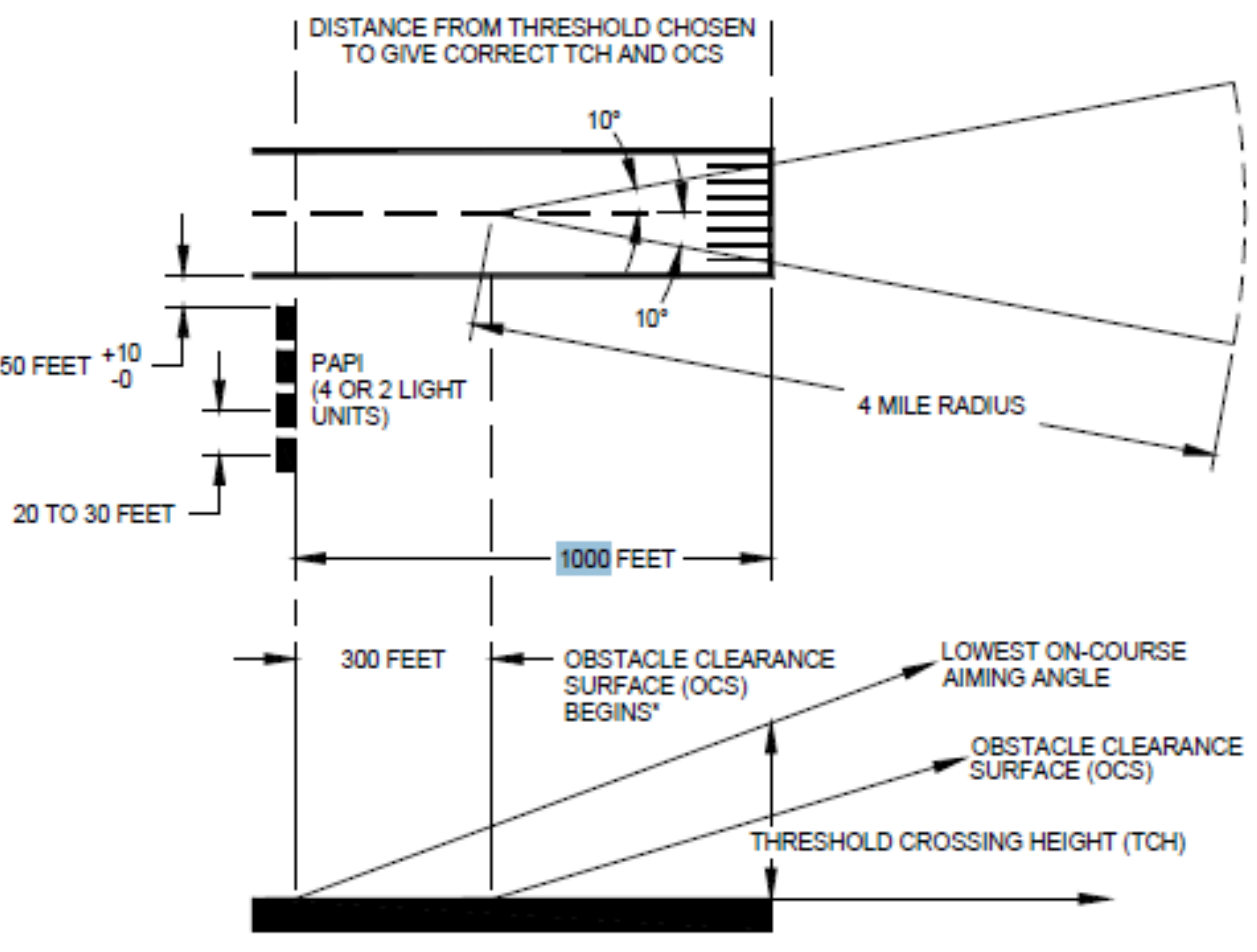

PAPI OCS ANGLE = LOWEST ON-COURSE AIMING ANGLE - 1 DEGREE

NOTES:

1. THE VSUAL GLIDE PATH ANGLE IS THE CENTER OF THE ON-COURSE ZONE, AND IS A NOMINAL 3 DEGREES WHEN MEASURED

A. FOR NONJET RUNWAYS, THE GLIDE PATH MAY BE RAISED TO 4 DEGREES MAXIMUM TO PROVIDE OBSTACLE CLEARANCE

B. IF THE PAPI GLIDE PATH IS CHANGED TO A HIGHER ANGLE FROM THE NOMINAL 3 DEGREES, IT MUST BE COMMUNICATED

2. PAPI OBSTACLE CLEARANCE SURFACE (OCS).

A. THE PAPI OCS PROVIDES THE PILOT WITH A MINIMUM APPROACH CLEARANCE.

B. THE PAPI MUST BE POSITIONED AND AIMED SO NO OBSTACLES PENETRATE ITS SURFACE,

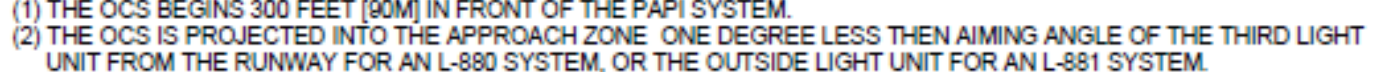

SUBJ: Visual Guidance Lighting Systems

This order contains installation criteria for all visual guidance lighting systems installed under the
Facilities and Equipment $(\mathrm{F} E)$ ) Program. This order was revised to Revision $B$ and includes

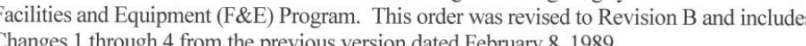

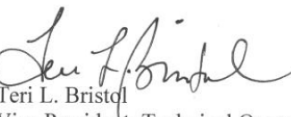

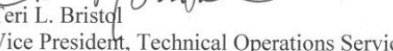




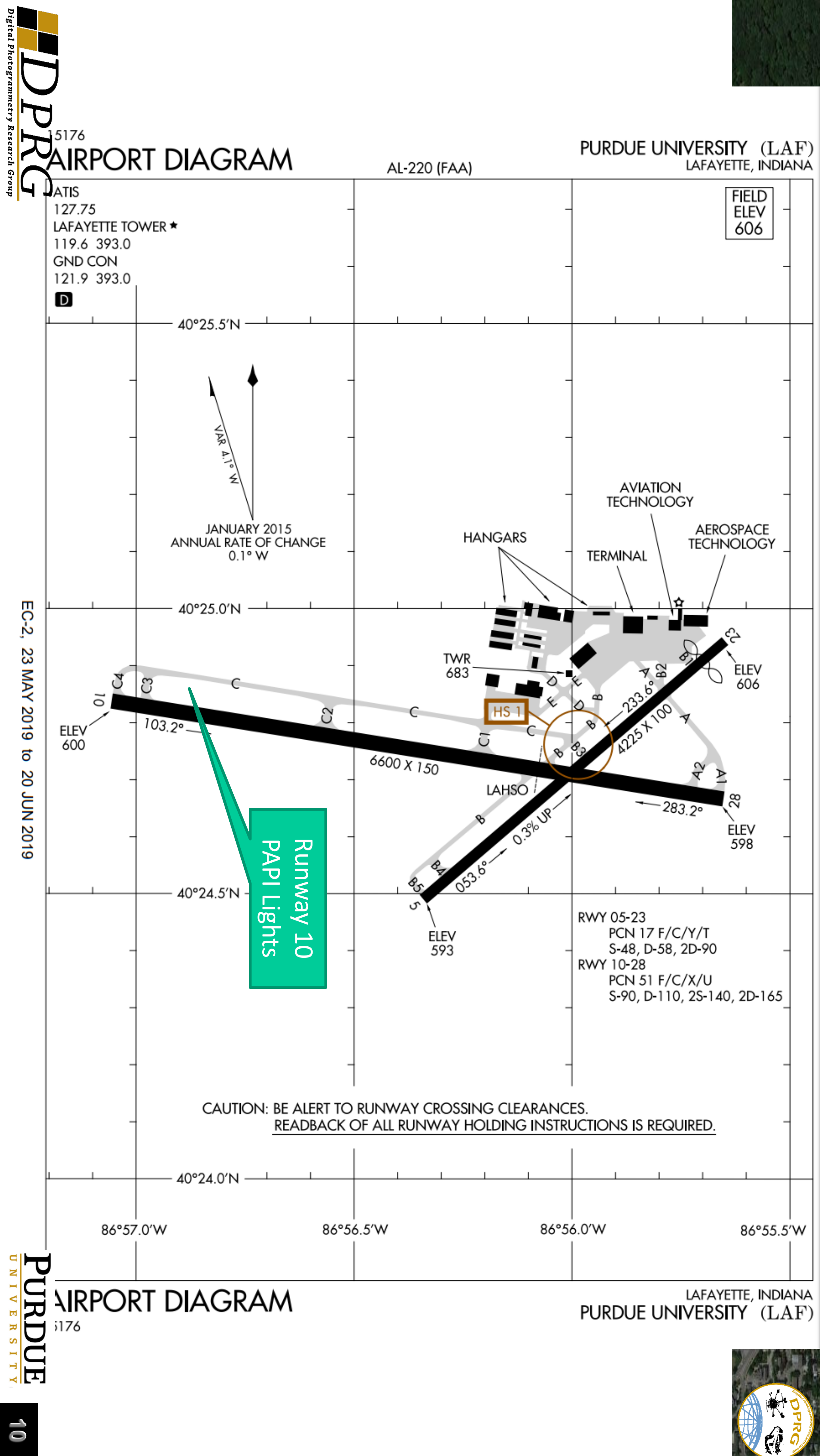





\section{PAPI Light Concêpt (3)}

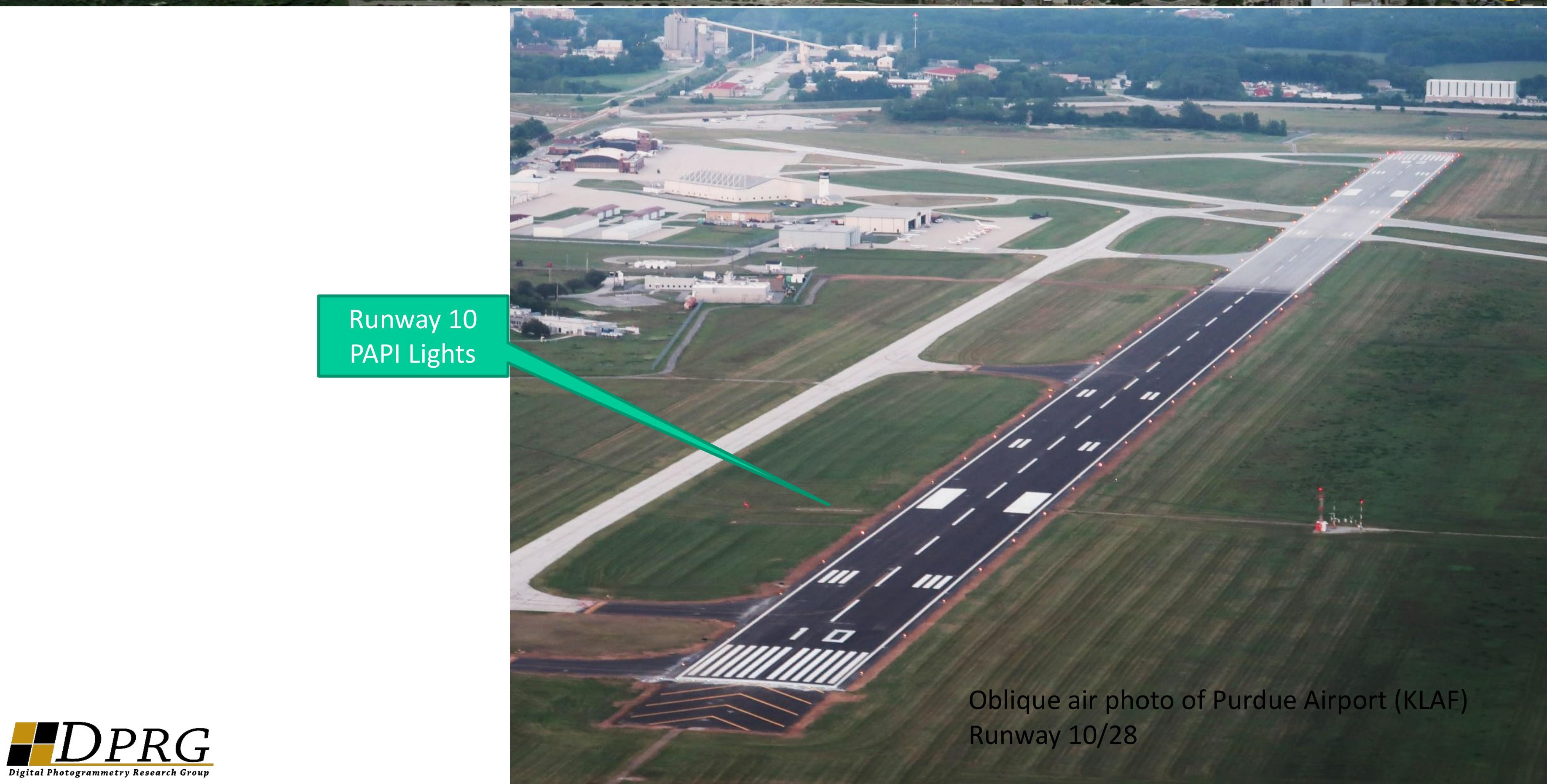




\section{PAPI Light Concềt $(4) \cup 1$}

\section{- Front Side of Runway 10 PAPI Lights}




\section{PAPI Light Concept (5)}

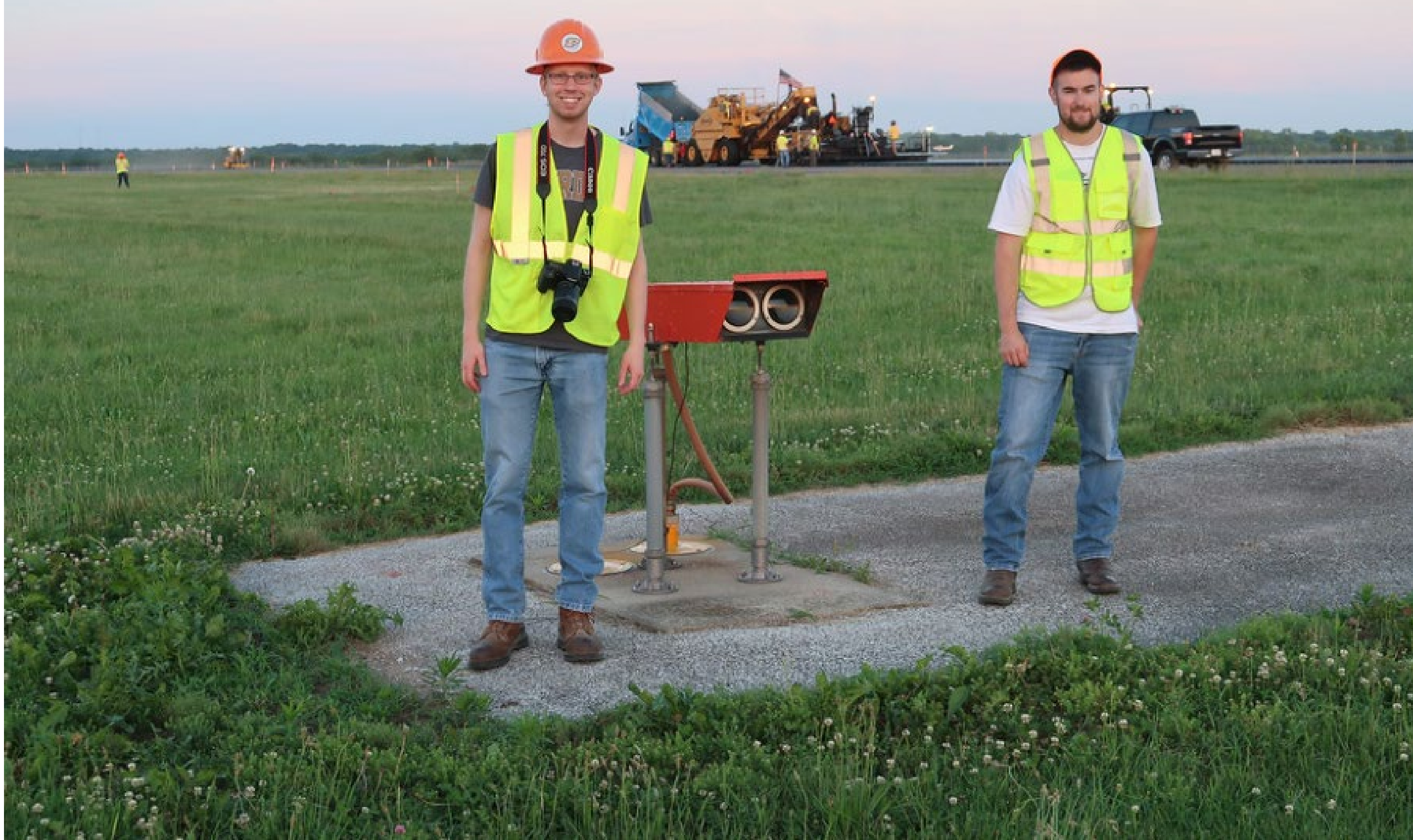




\section{PAPI Light Concept (6)}

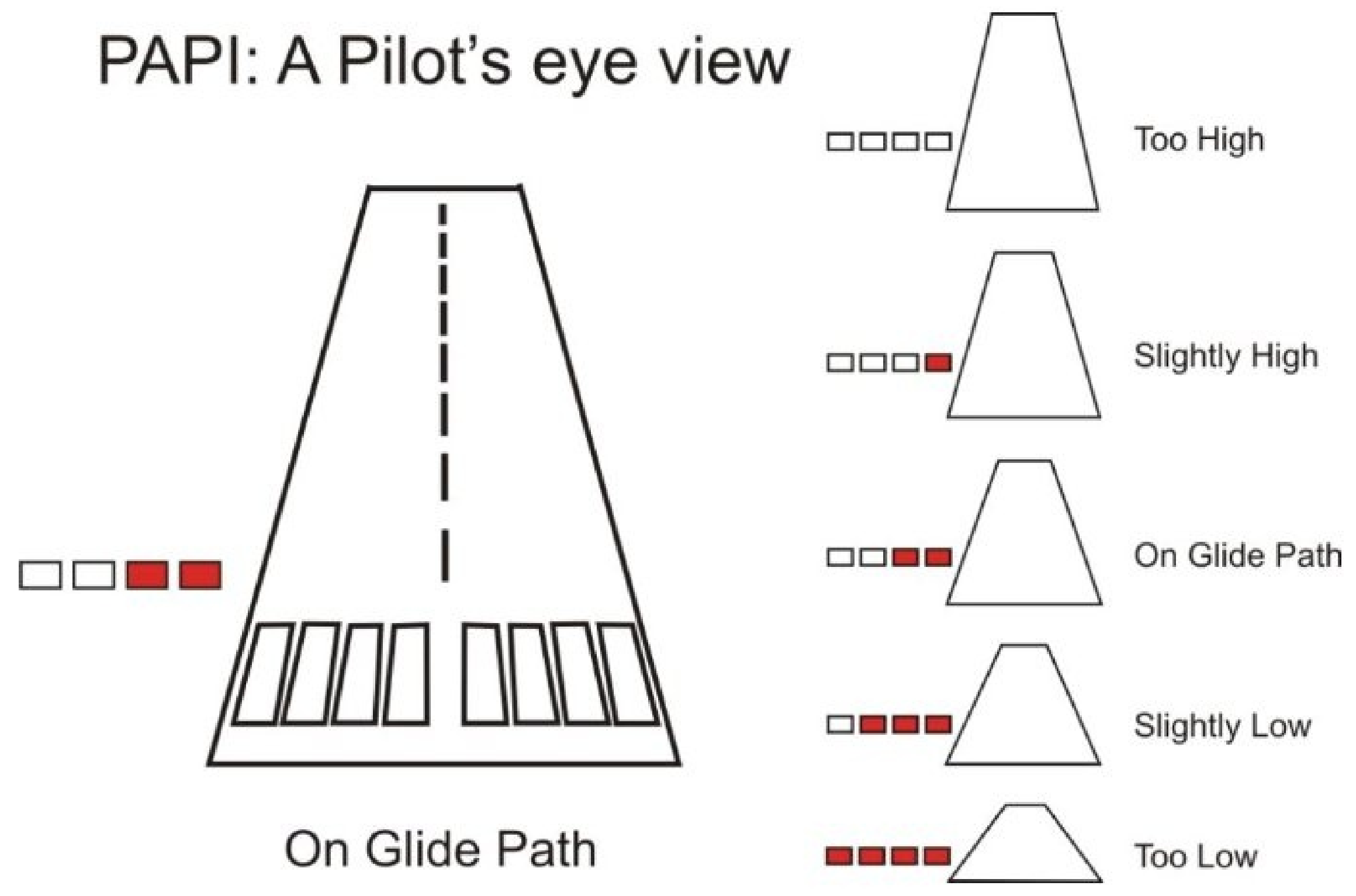


1. Research Team

2. Problem Statement

$$
\text { PAPI (PI, P2, P3) }
$$

APAPI (AP)

3. PAPI Light Concept

4. PAPI Light Images from Left Seat of Cessna 170

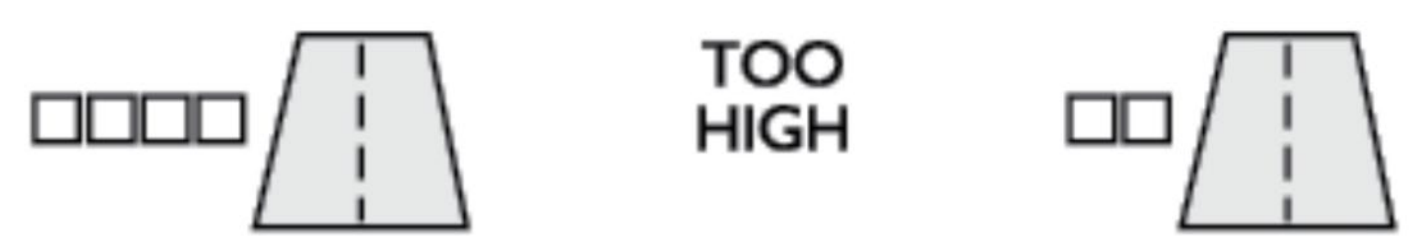

5. Surveying Procedures

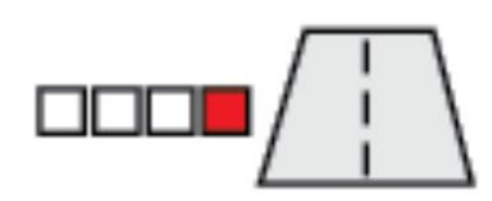

SLIGHTLY $\mathrm{HIGH}$

6. PAPI Light Images from UAS

7. Glideslope Angle Estimate

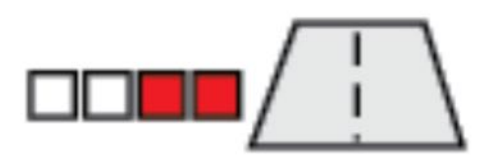

ON CORRECT APPROACH PATH

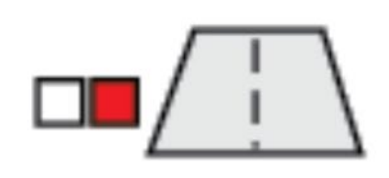

8. Conclusion and Ongoing Implementation Activities

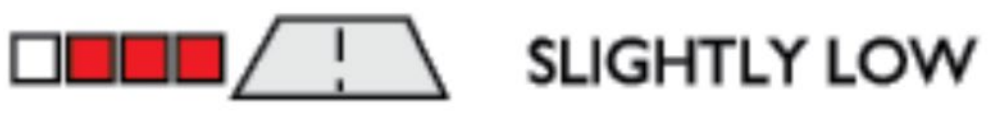

$\square \square \square$ TOO LOW

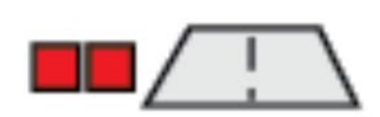




\section{Our Purdue Pilot}

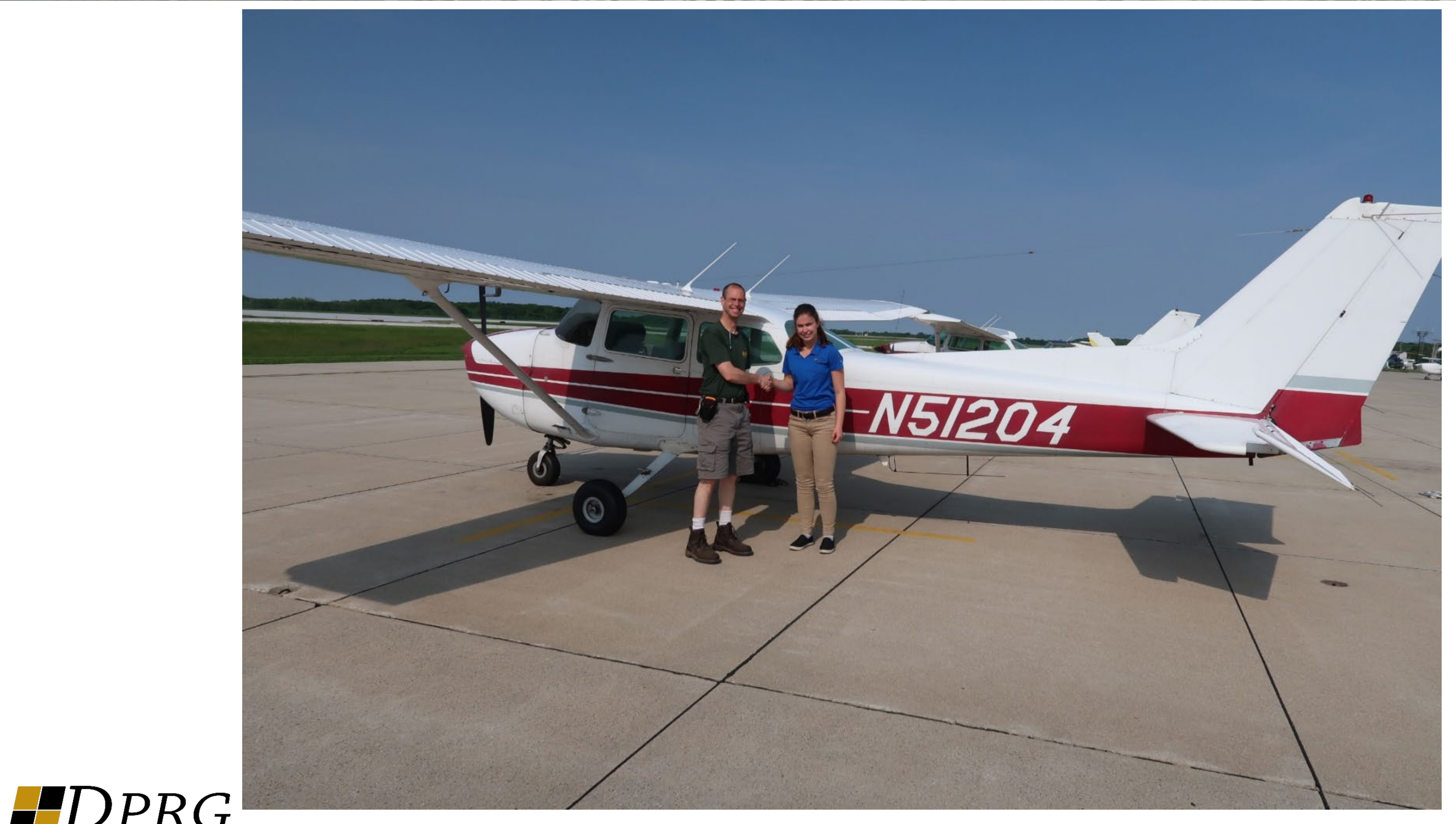




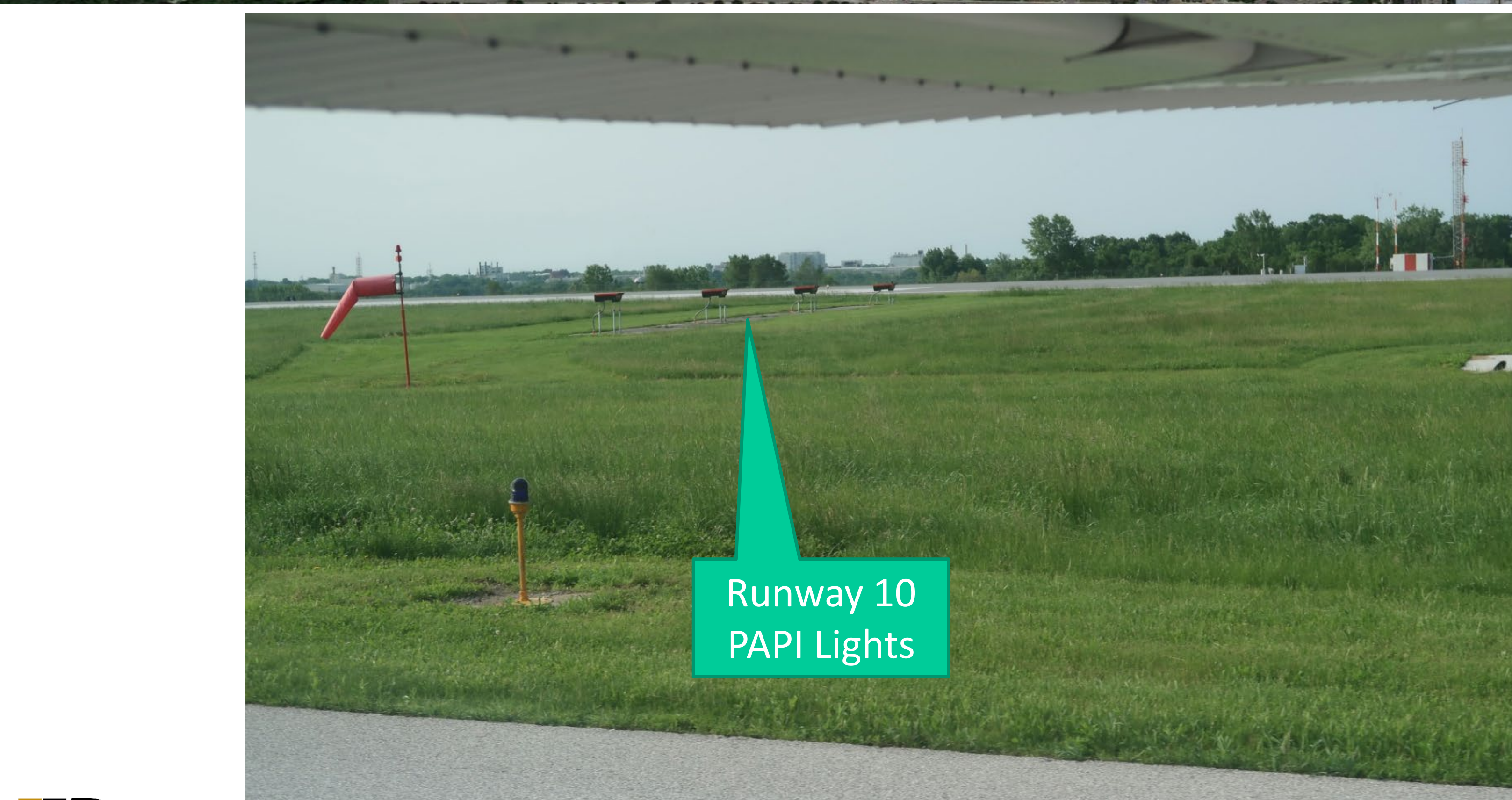


UAS with high quality position locates will be more cost effective and likely more robust over entire envelope

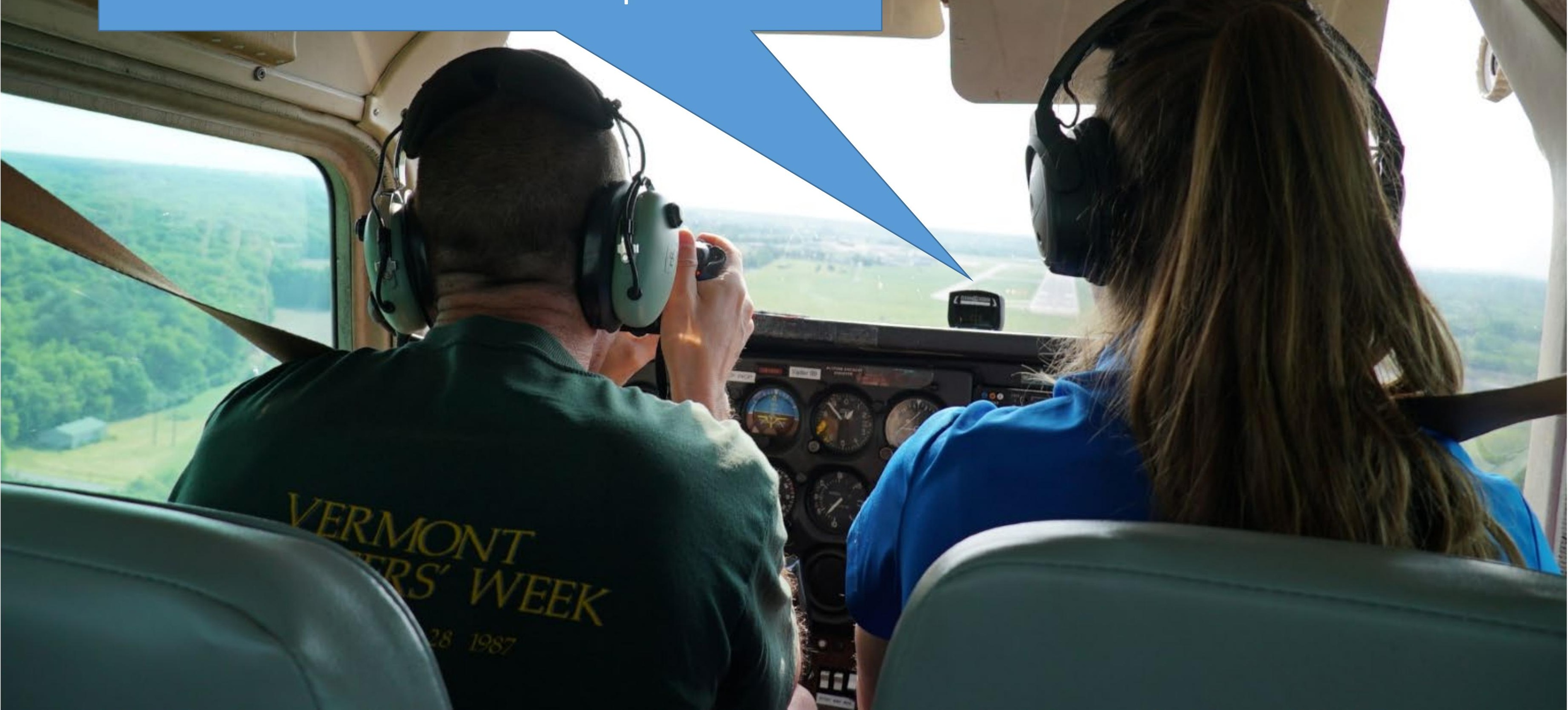




\section{PAPI Light Concêpt (7)}

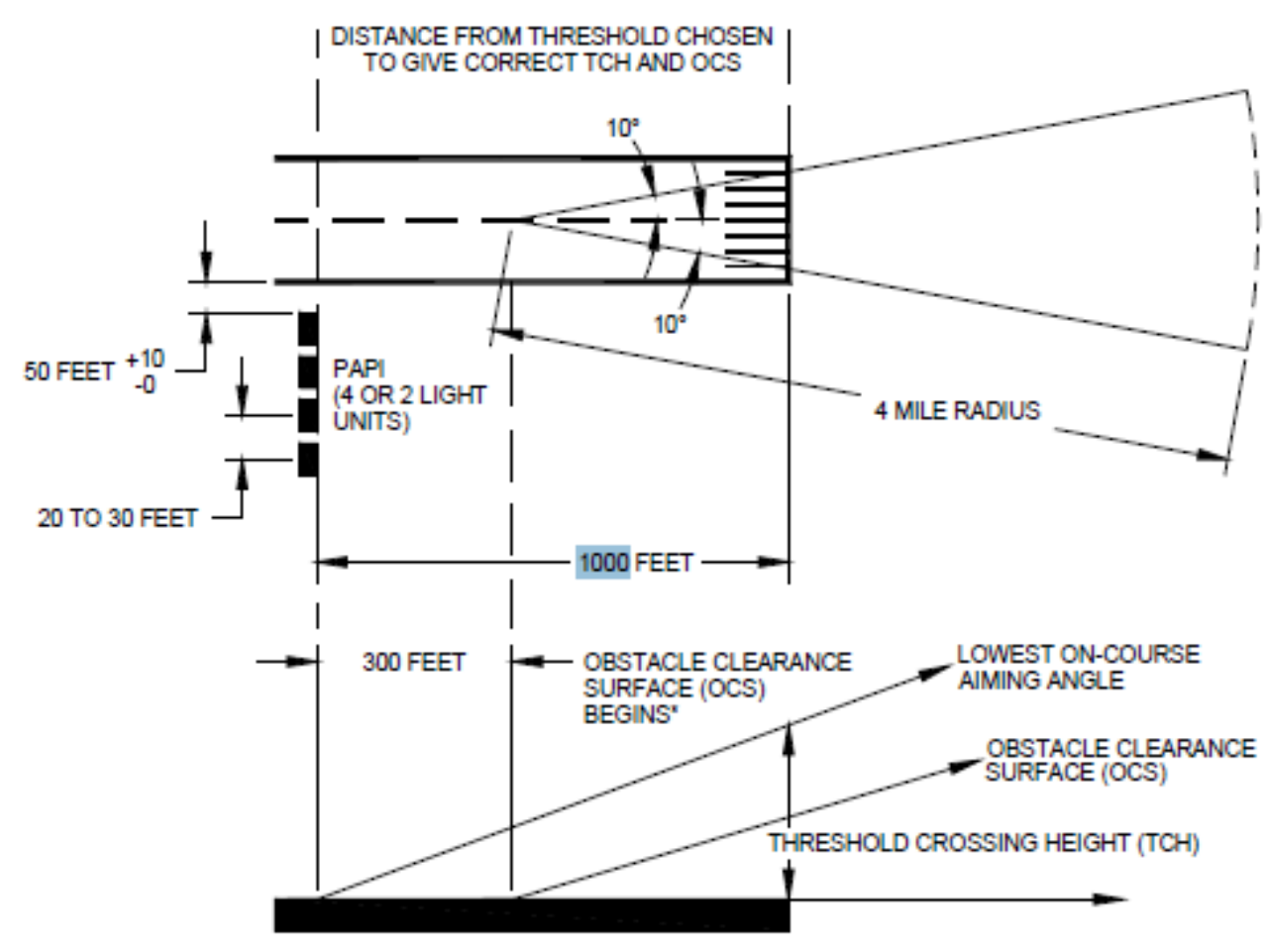

PAPI OCS ANGLE = LOWEST ON-COURSE AIMING ANGLE - 1 DEGREE

NOTES:

1. THE VSUAL GLIDE PATH ANGLE IS THE CENTER OF THE ON-COURSE ZONE, AND IS A NOMINAL 3 DEGREES WHEN MEASURED FROM THE

A. FOR NON-JET RUNWAYS, THE GLIDE PATH MAY BE RAISED TO 4 DEGREES MAXIMUM TO PROVIDE OBSTACLE CLEARANCE B. IF THE PAPI GLIDE PATH IS CHANGED TO A HIGHER ANGLE FROM THE NOMINAL 3 DEGREES, IT MUST BE COMMUNICATED

2. PAPI OBSTACLE CLEARANCE SURFACE (OCS).

A. THE PAPI OCS PROVIDES THE PILOT WITH A MINIMUM APPROACH CLEARANCE.

B. THE PAPI MUST BE POSITIONED AND AIMED SO NO OBSTACLES PENETRATE ITS SURFACE

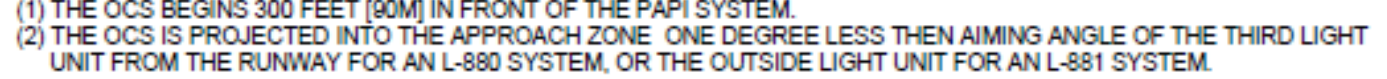

U.S. DEPARTMENT OF TRANSPORTATION
FEDERALAVIATION ADMINISTRATION

Air Traffic Organization Polic 


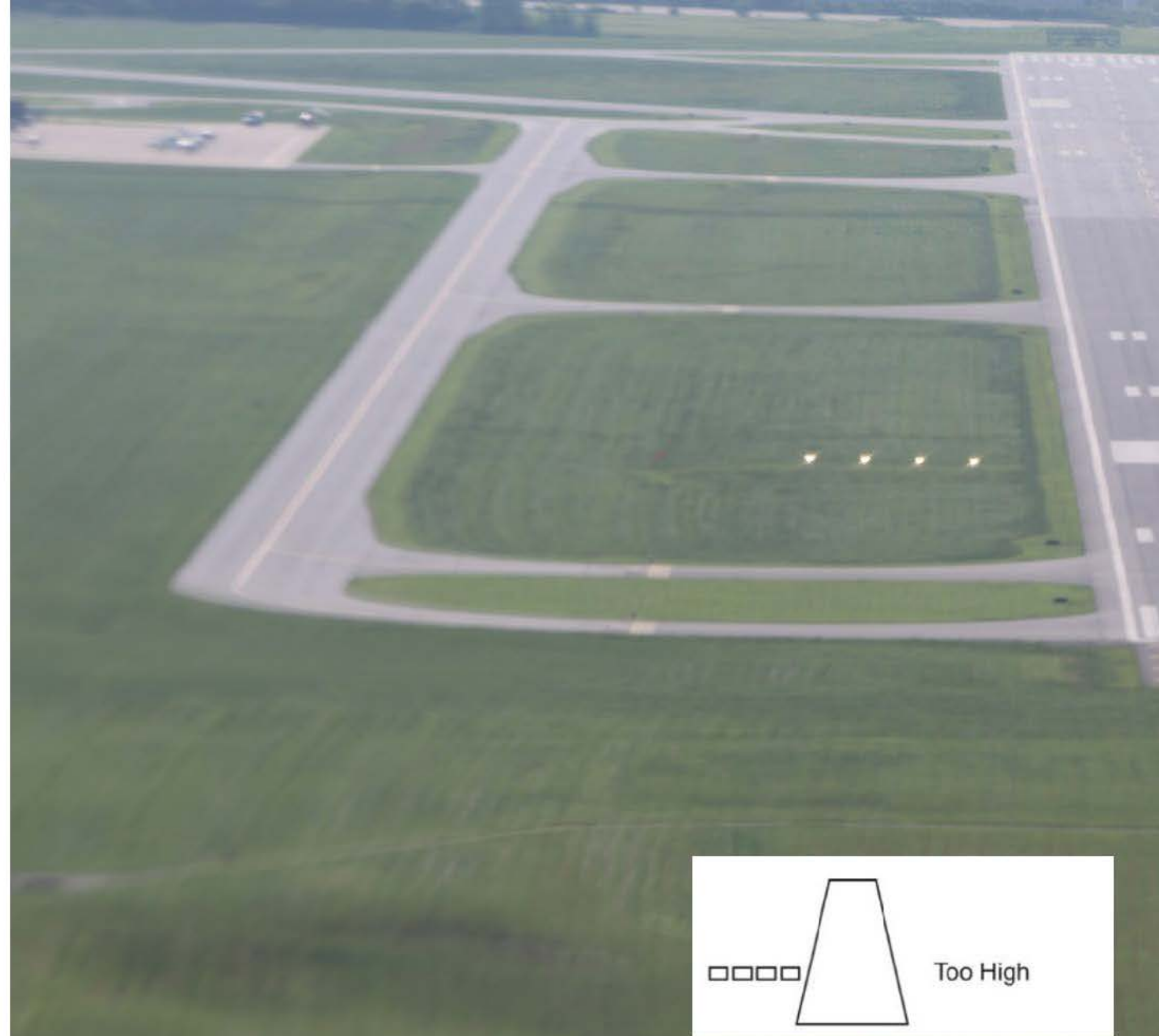




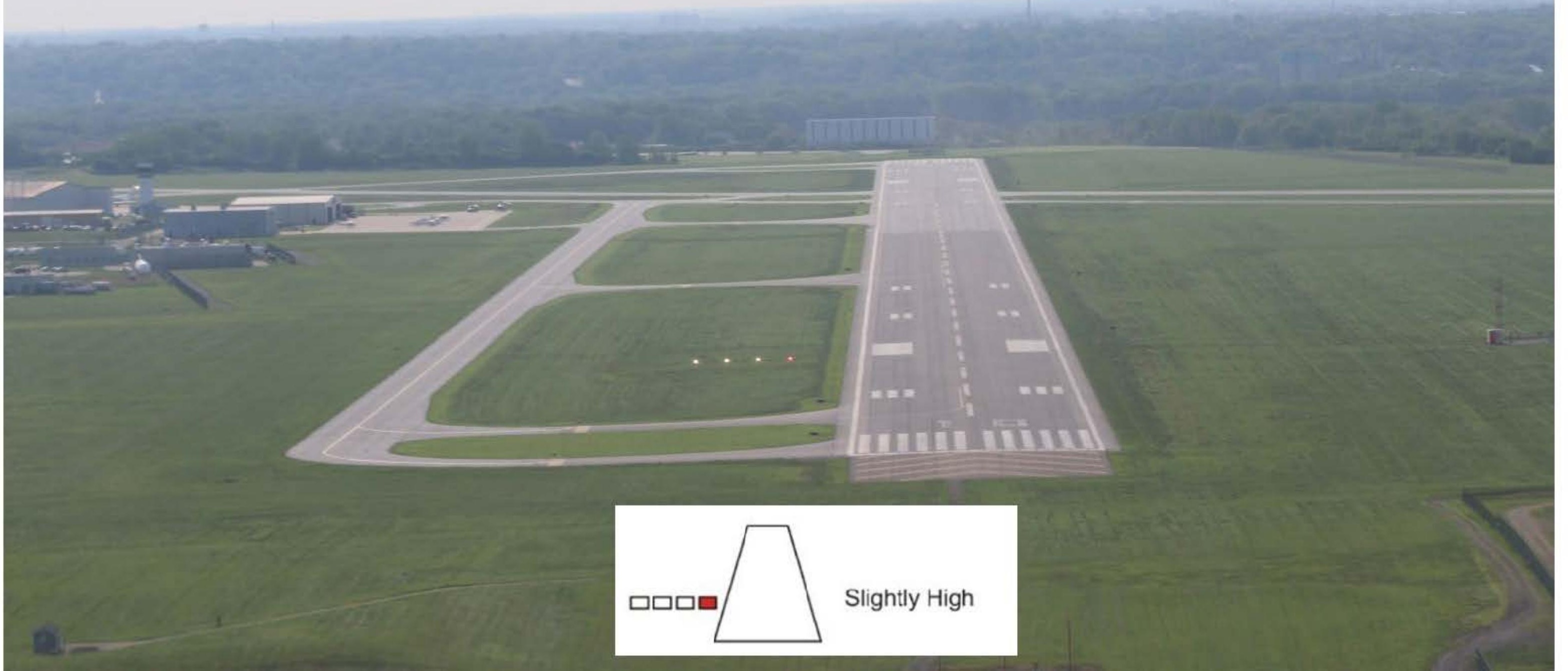




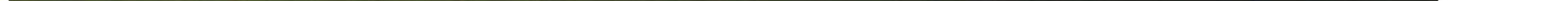




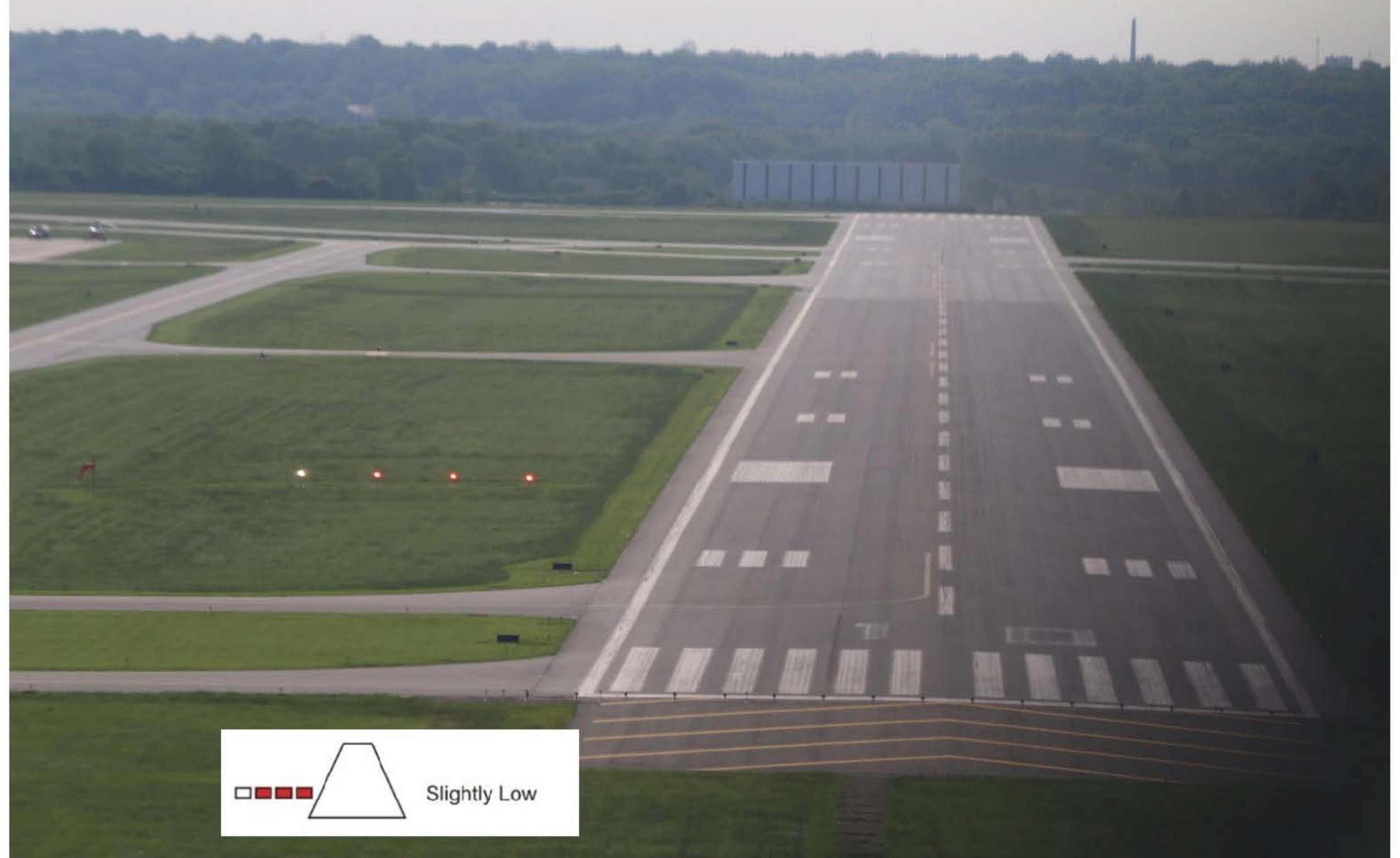




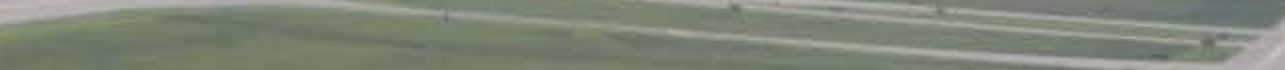

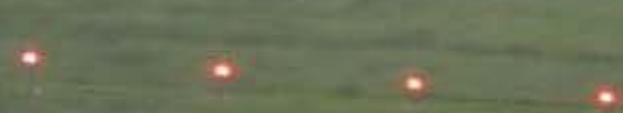

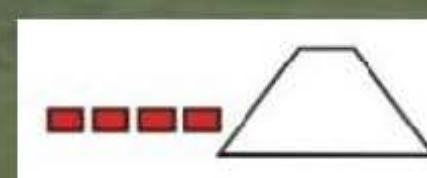

ロேロ \ Too Low

$--$

$20-20$

men
$-$

$=$

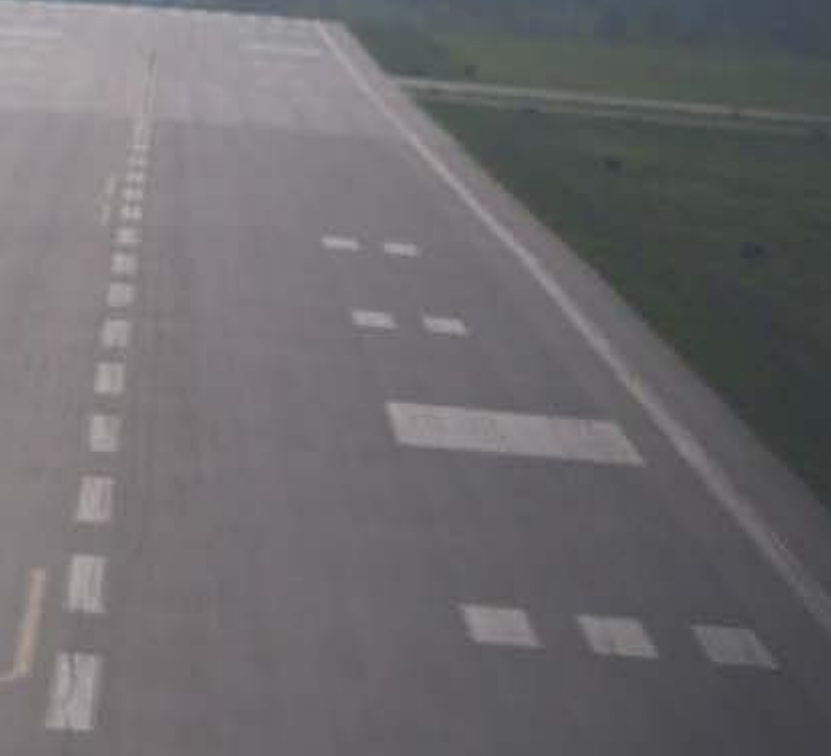

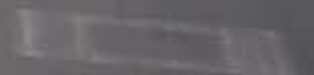




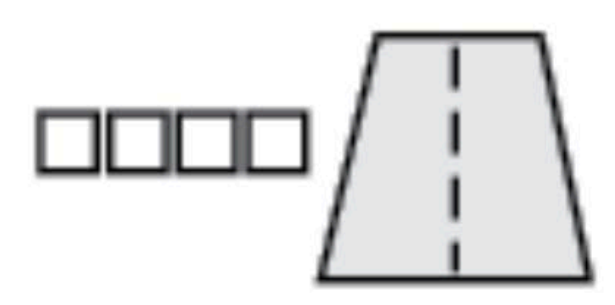

$$
\text { TOO }
$$
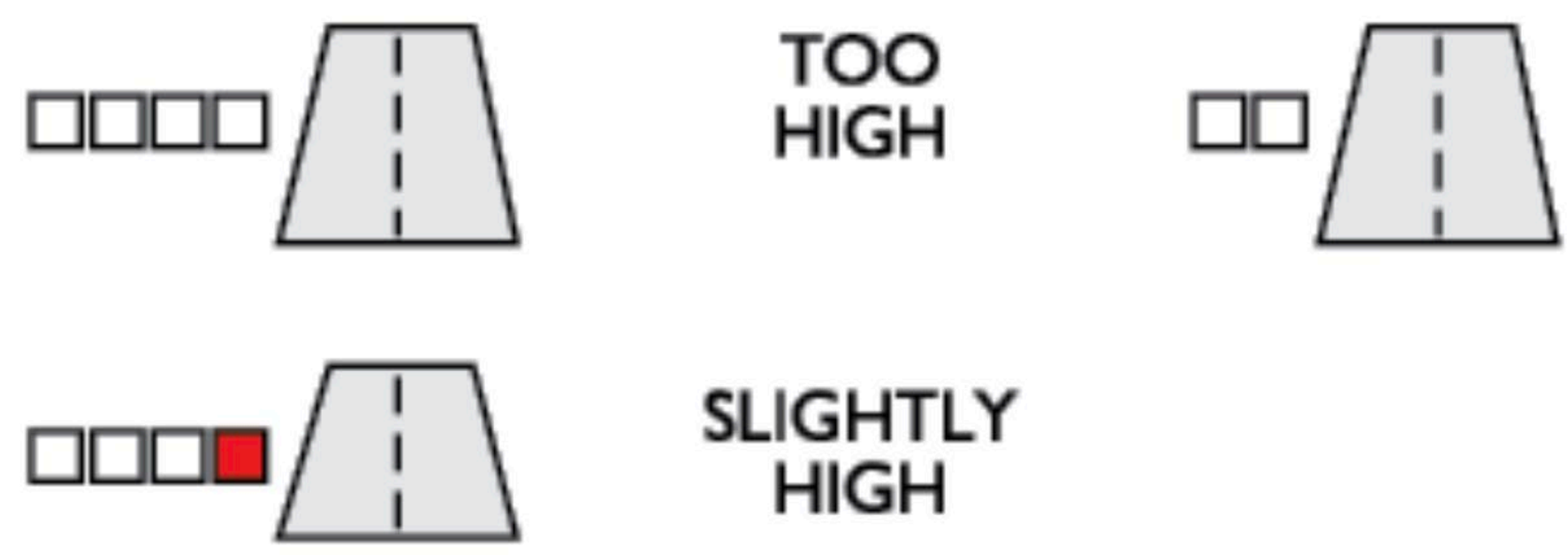

SLIGHTLY $\mathrm{HIGH}$

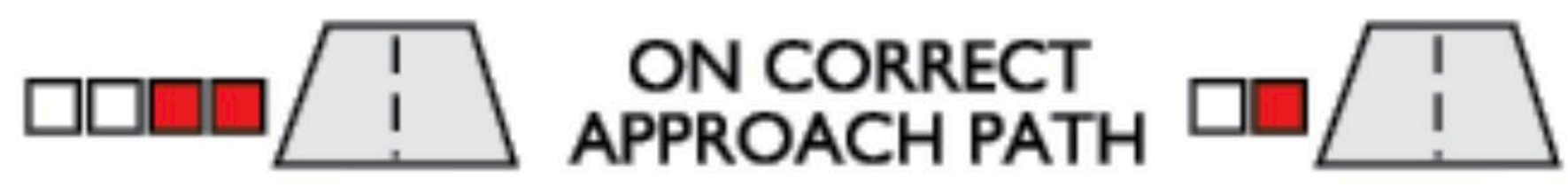

$\square \square \square \square$ SLIGHTLY LOW

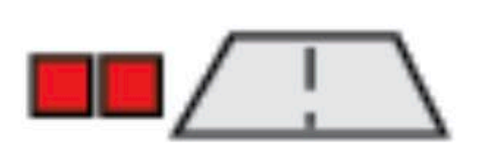




\section{Topics (4)}

1. Research Team

2. Problem Statement

3. PAPI Light Concept

4. PAPI Light Images from Left Seat of Cessna 170

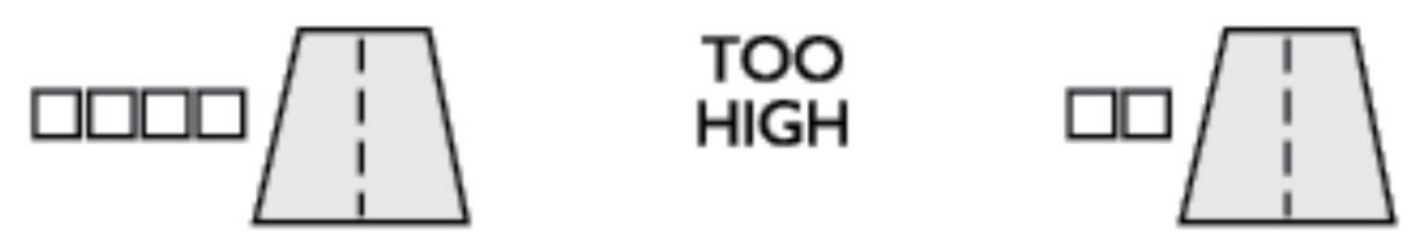

5. Surveying Procedures

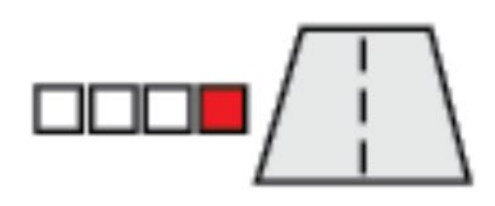

SLIGHTLY $\mathrm{HIGH}$

6. PAPI Light Images from UAS

7. Glideslope Angle Estimate

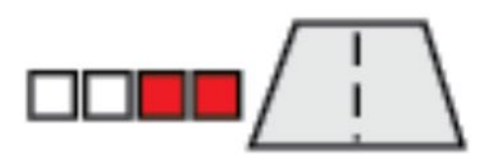

ON CORRECT APPROACH PATH

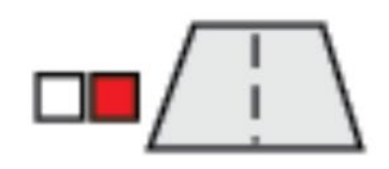

8. Conclusion and Ongoing Implementation Activities

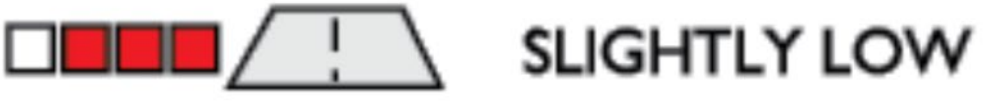




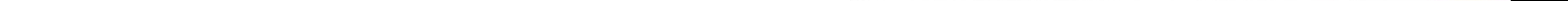




\section{Transition Elevatiöns at $400 \mathrm{ft}$ and $2000 \mathrm{ft}$}

\begin{tabular}{|r|l|r|r|}
\hline Angle & Dec & 1000 & 2000 \\
\hline 3.5 & 0.061163 & 61.16 & 122.33 \\
\hline 3.17 & 0.055383 & 55.38 & 110.77 \\
\hline 3 & 0.052408 & 52.41 & 104.82 \\
\hline 2.83 & 0.049433 & 49.43 & 98.87 \\
\hline 2.5 & 0.043661 & 43.66 & 87.32 \\
\hline
\end{tabular}

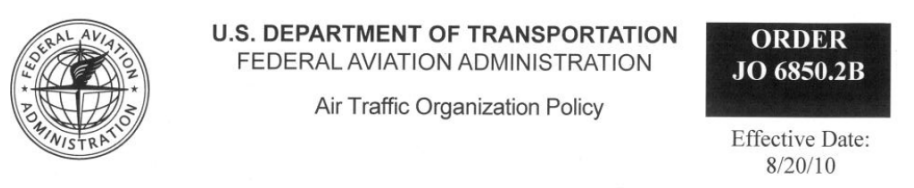

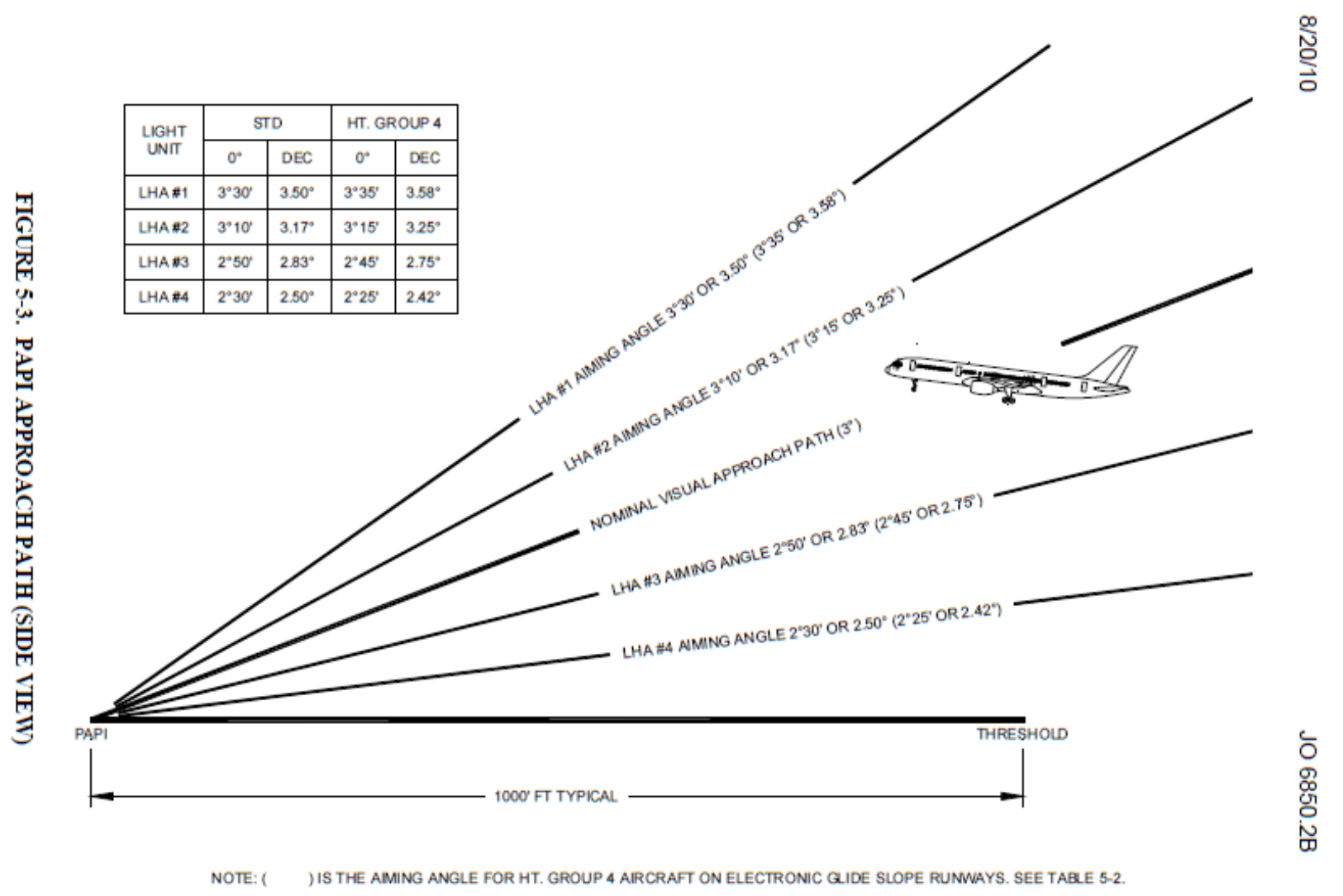


1. Research Team

2. Problem Statement

$$
\text { PAPI (PI, P2, P3) }
$$

APAPI (AP)

3. PAPI Light Concept

4. PAPI Light Images from Left Seat of Cessna 170
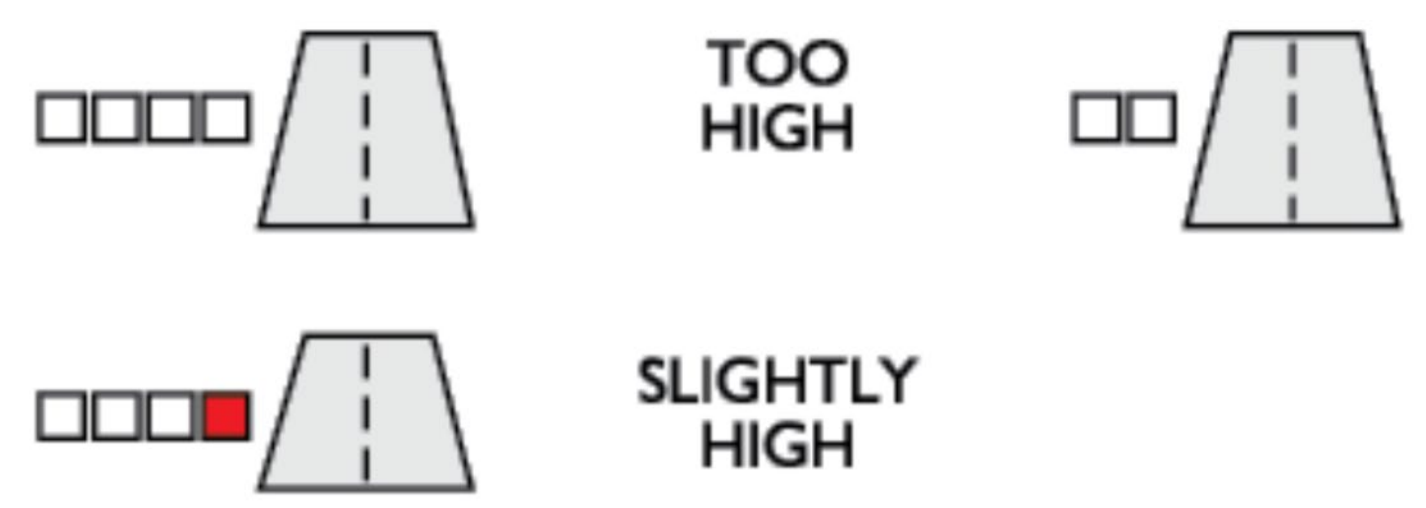

SLIGHTLY $\mathrm{HIGH}$

6. PAPI Light Images from UAS

7. Glideslope Angle Estimate

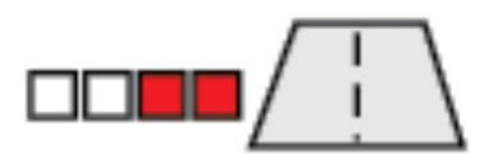

ON CORRECT APPROACH PATH

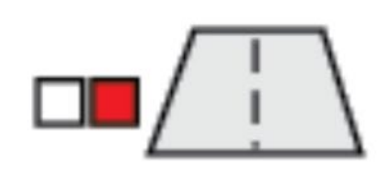

8. Conclusion and Ongoing Implementation Activities

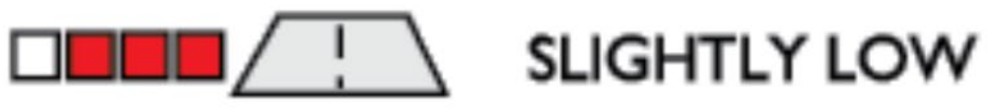









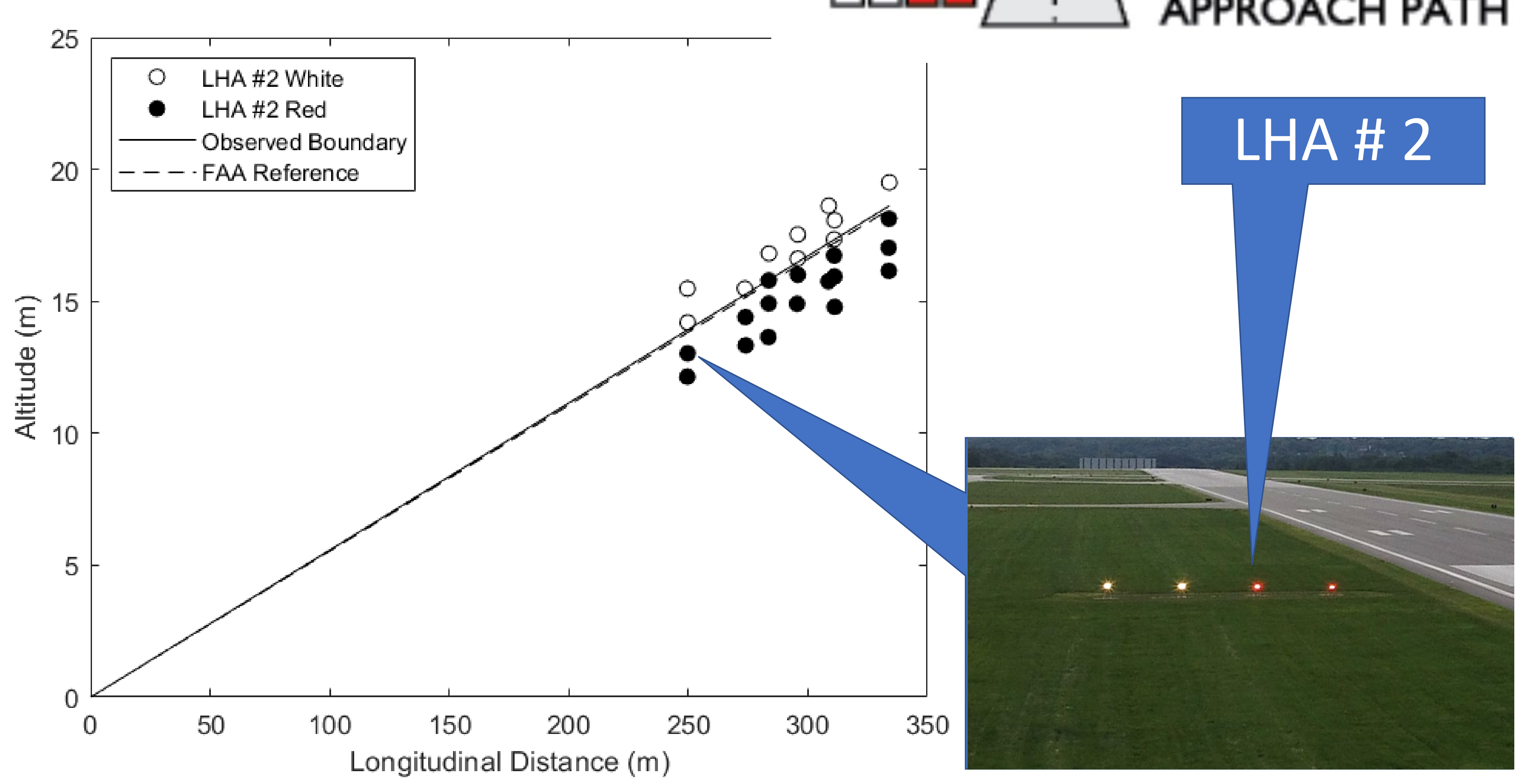




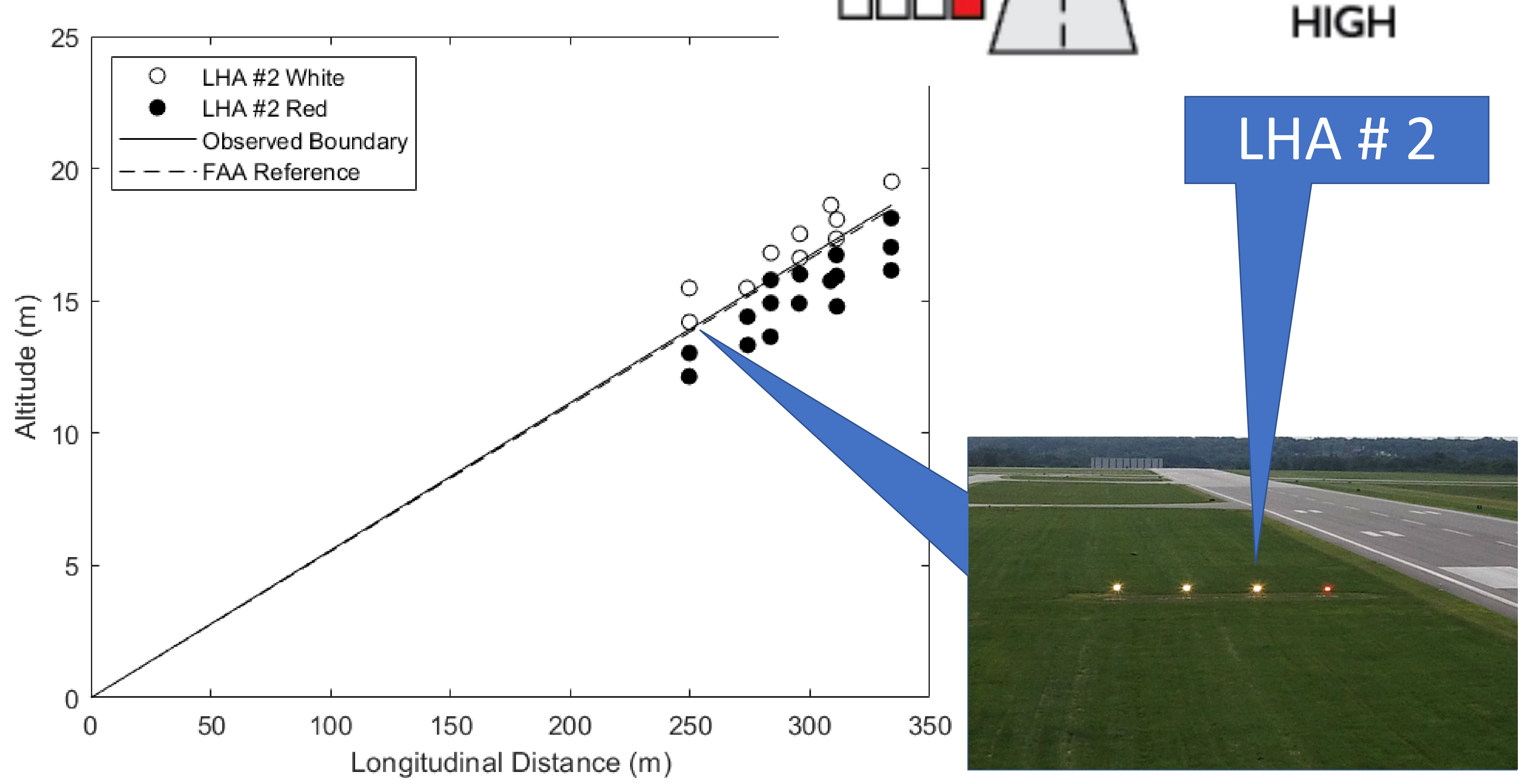




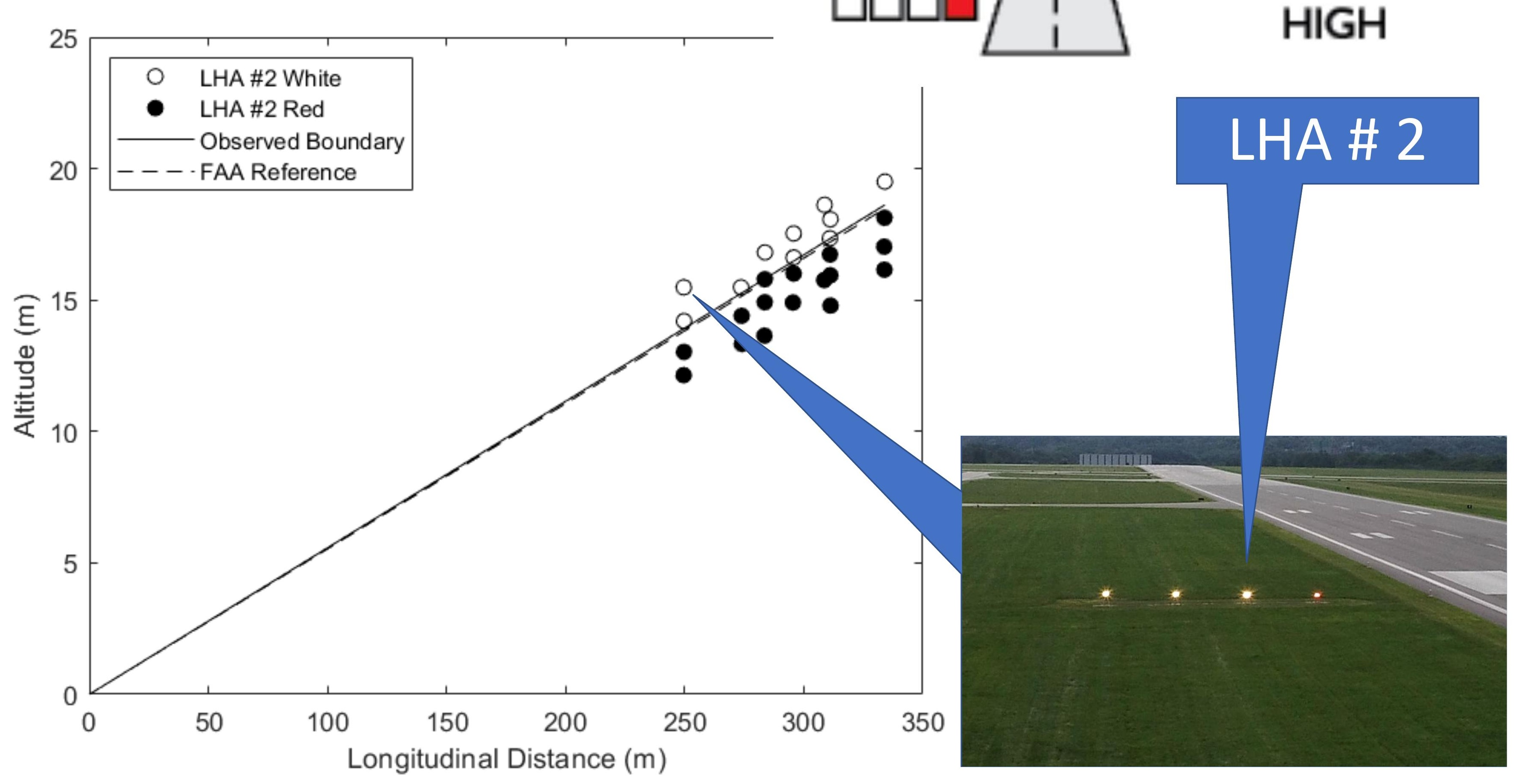




\section{Field Procedure}

- Fly the UAS at different locations and altitudes and take images of the PAPI system

- Survey the UAS positions using (two) independent total stations

UAS with survey prism mounted

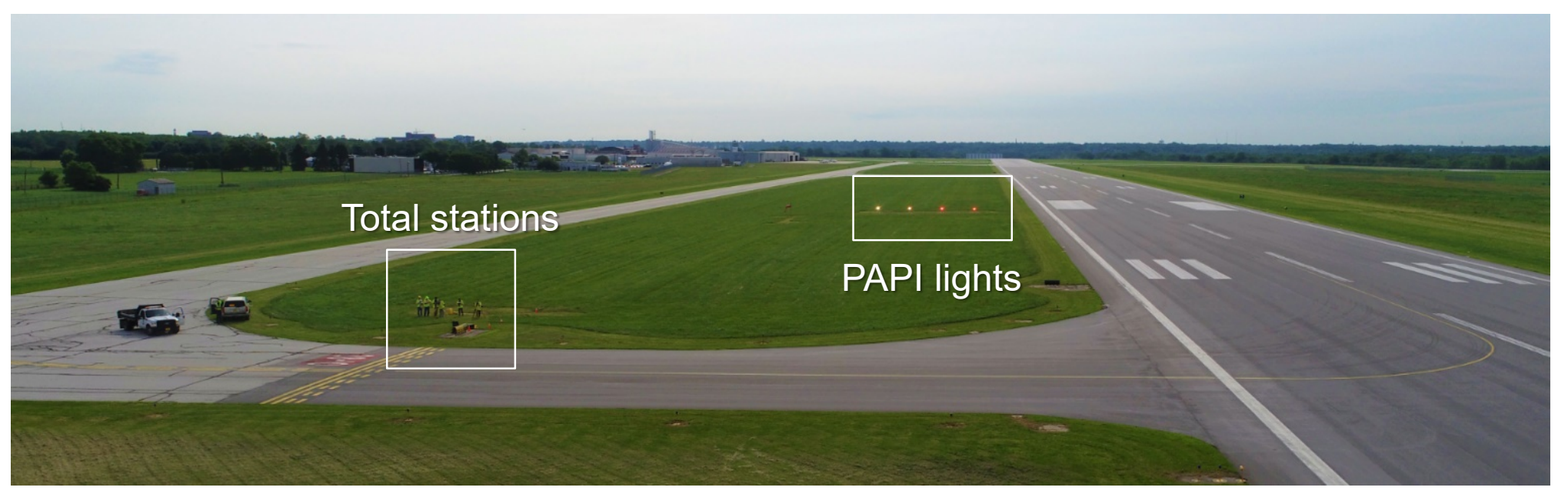

UAS image shows the total stations and PAPI lights
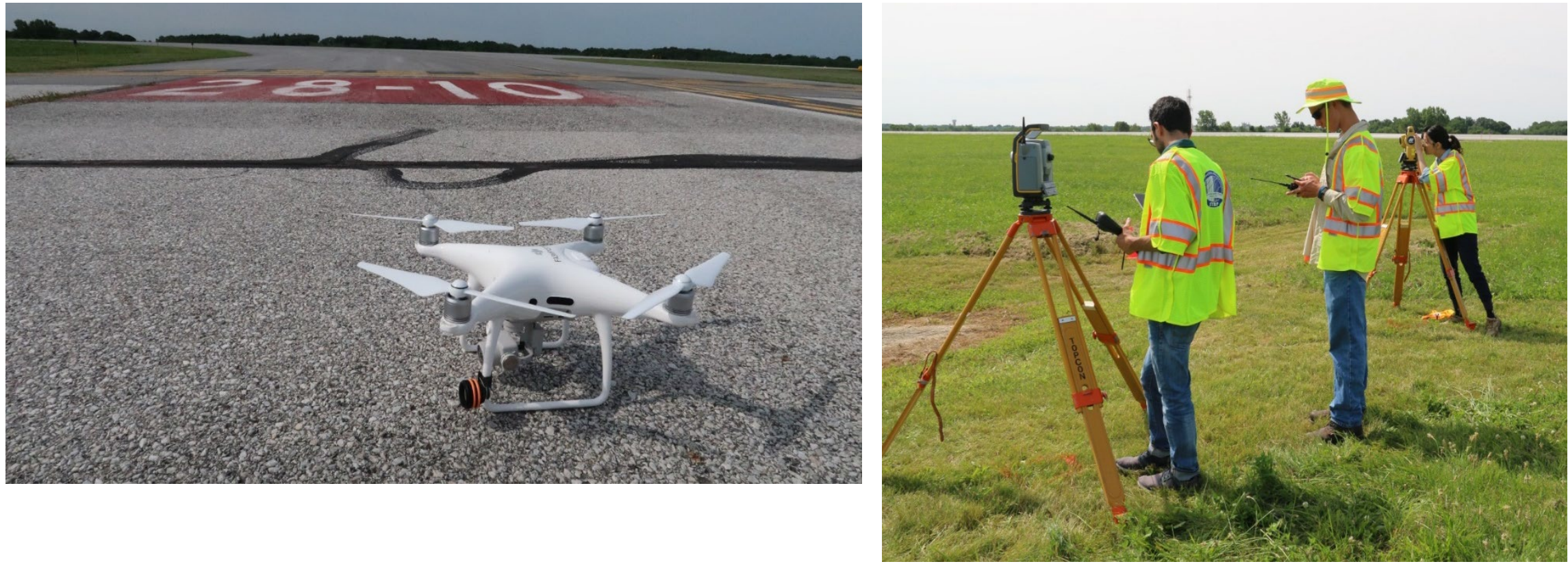

Total stations used

to locate UAS 


\section{PAPI Indications ând UAS linages}

PAPI light housing assemblies

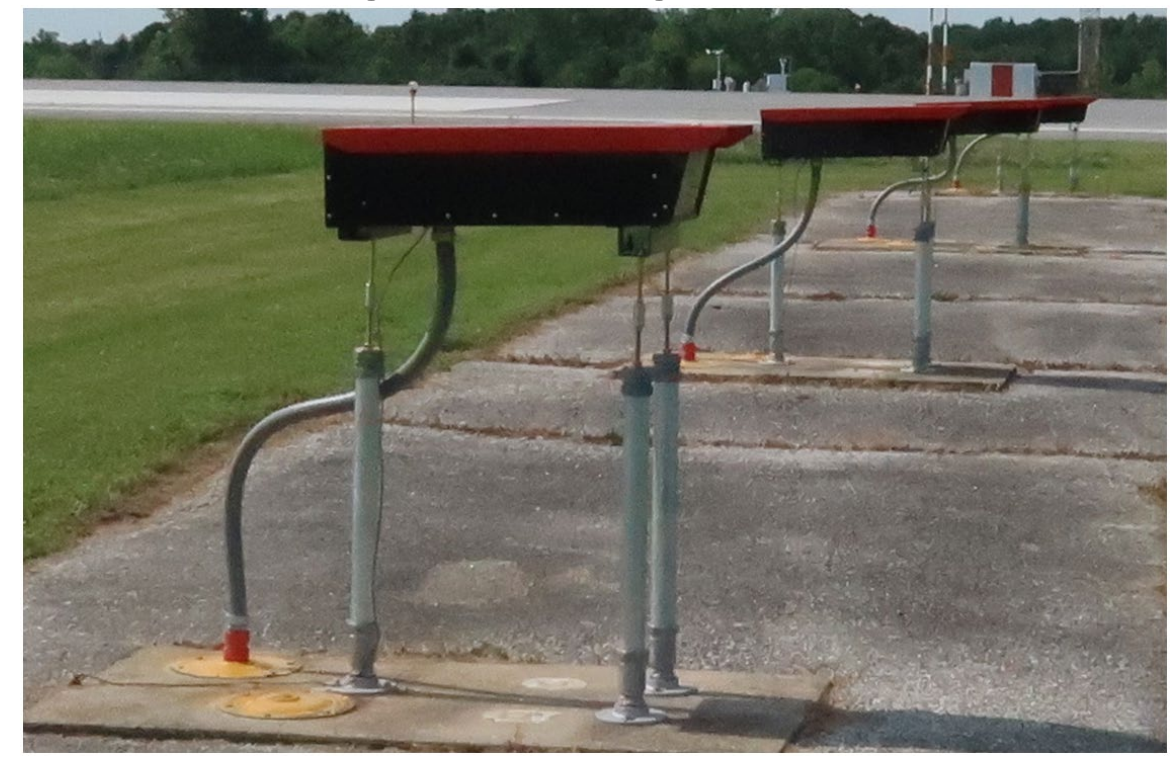

Two white, two red PAPI indications

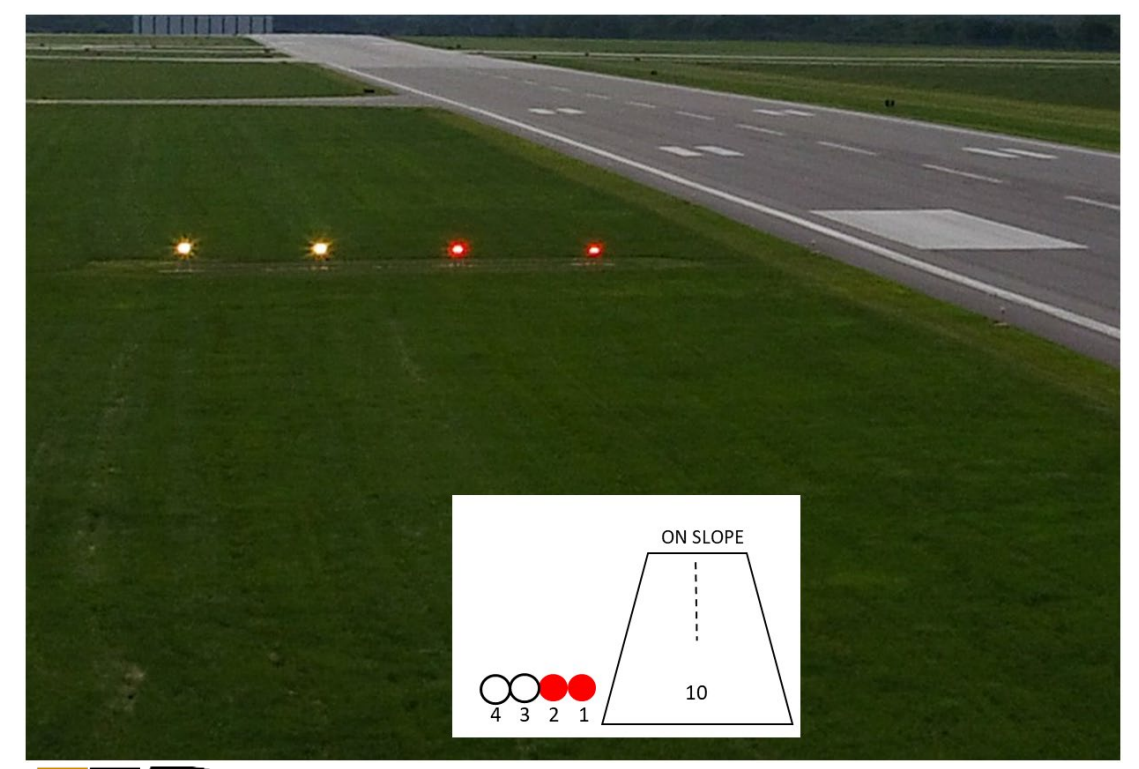

$D P R G$
Four white PAPI indications

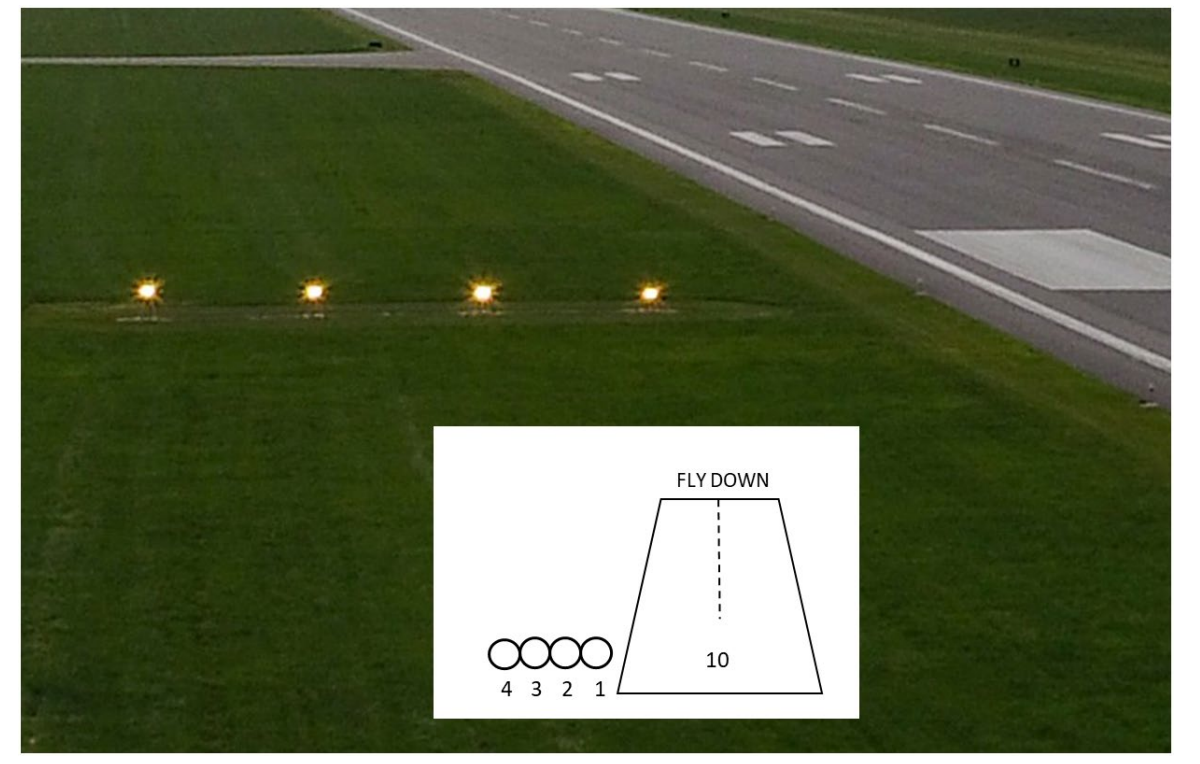

One white, three red PAPI indications

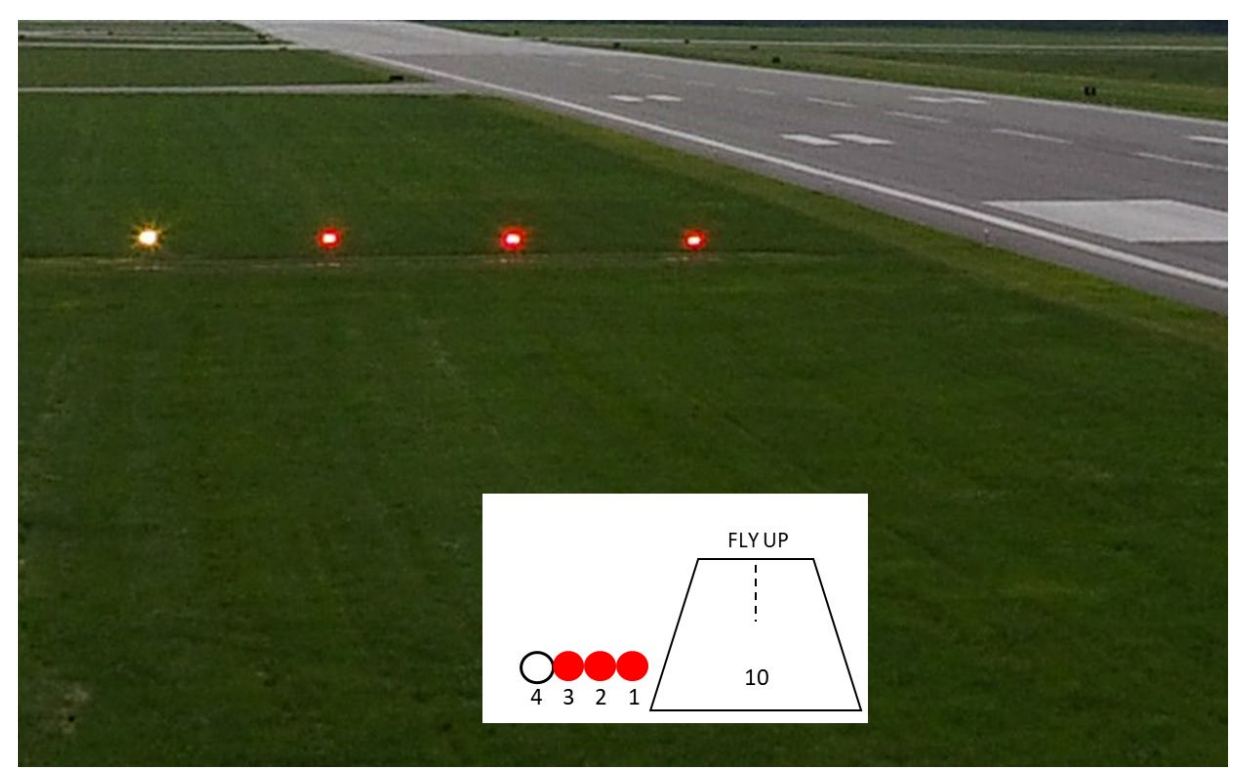

Three white, one red PAPI indications

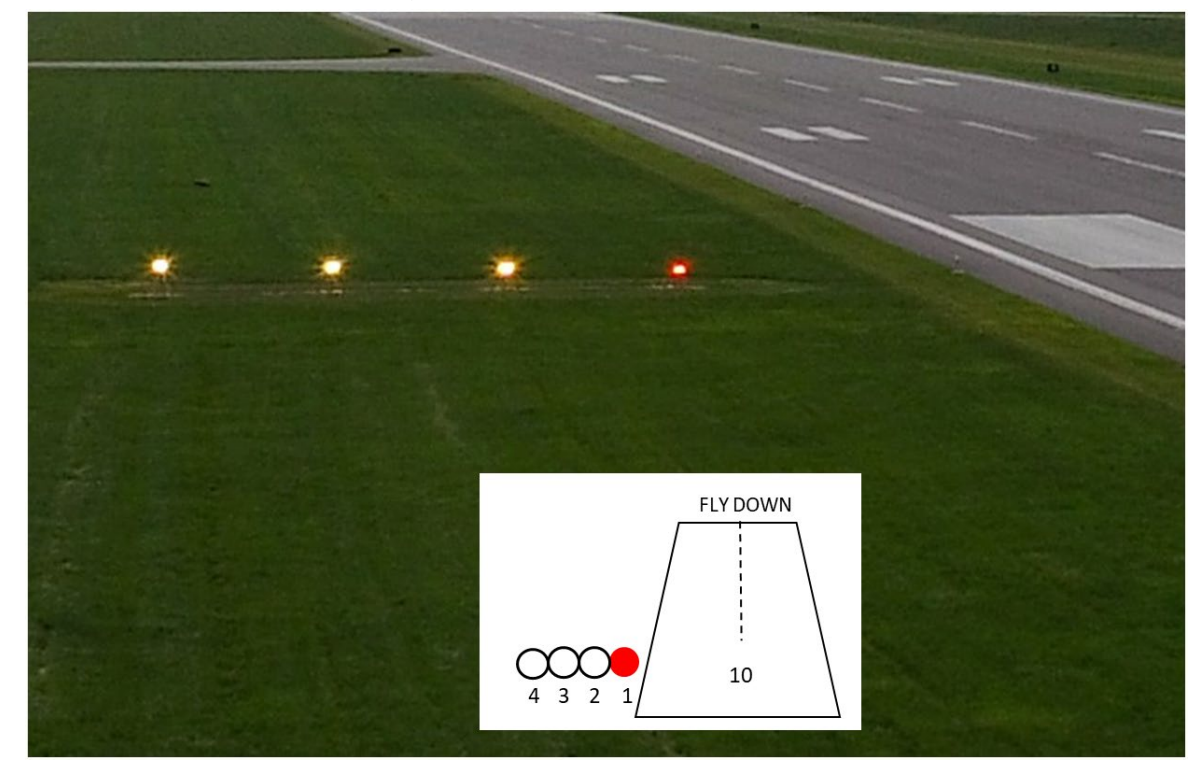

Four red PAPI indications

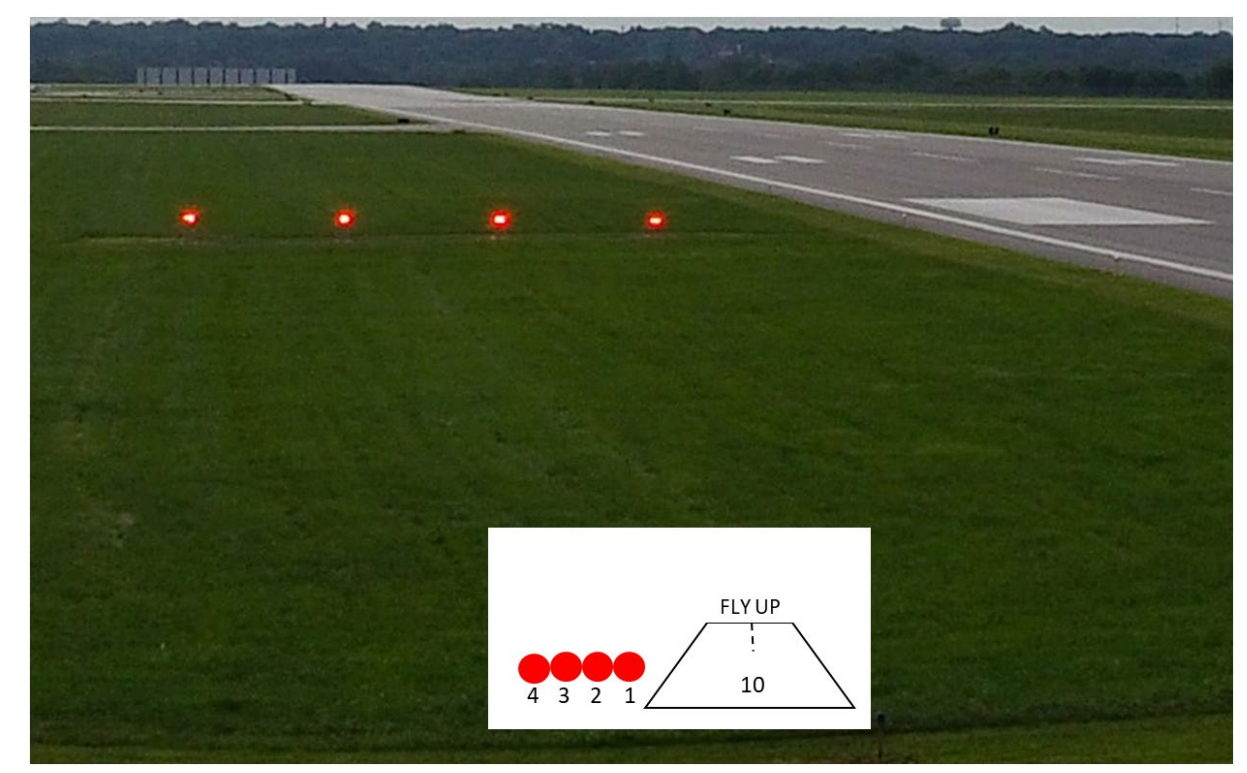

PURDUE 
1. Research Team

2. Problem Statement

$$
\text { PAPI (PI, P2, P3) }
$$

APAPI (AP)

3. PAPI Light Concept

4. PAPI Light Images from Left Seat of Cessna 170
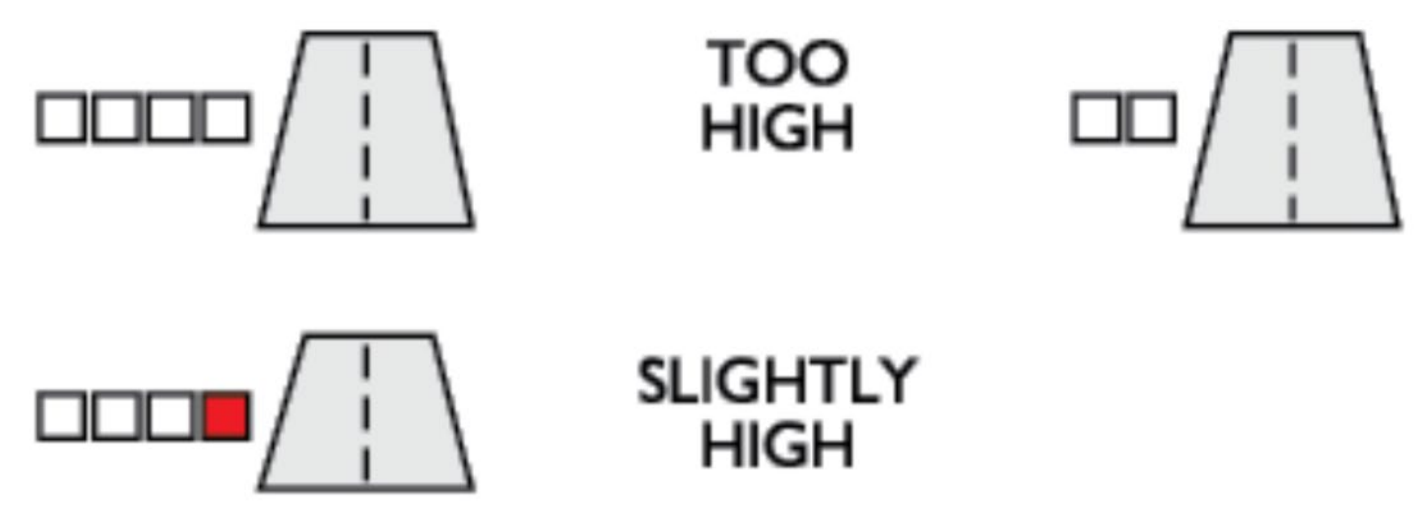

SLIGHTLY $\mathrm{HIGH}$

6. PAPI Light Images from UAS

7. Glideslope Angle Estimate

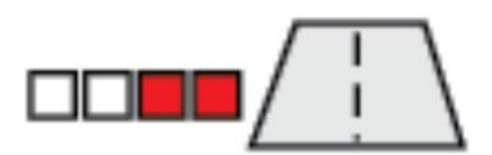

ON CORRECT APPROACH PATH

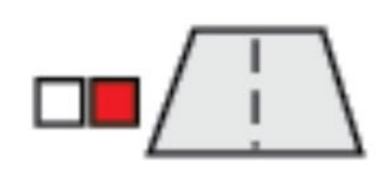

8. Conclusion and Ongoing Implementation Activities

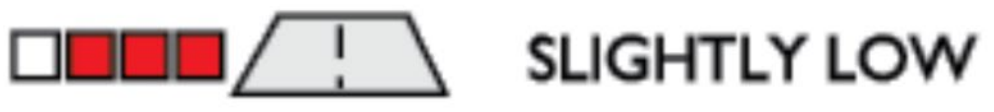

$\square \square \square$ TOO LOW

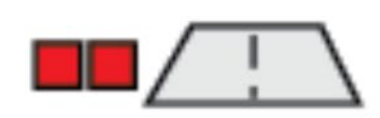




\section{Spatial Reference for -ach As lmage}

- Georeference total station measurements to UTM coordinate system using ground control points

- Decompose the total station angle and distance measurements into longitudinal (parallel to the runway) and lateral components

- Calculate glide slope and glide path angle

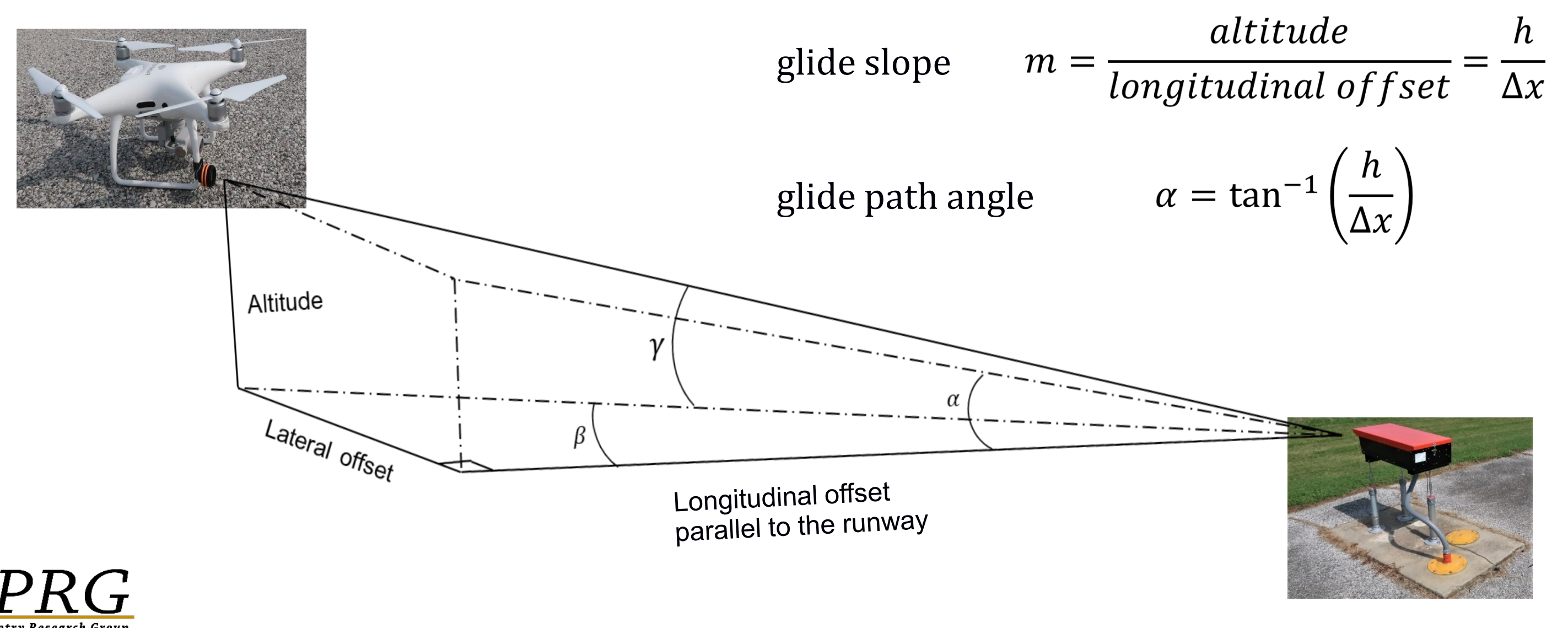




\section{Estimated Transition Angle}

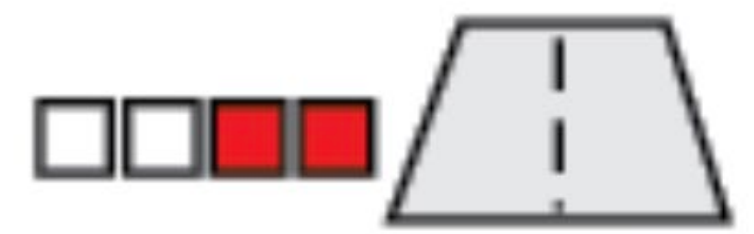

ON CORRECT
APPROACH PATH
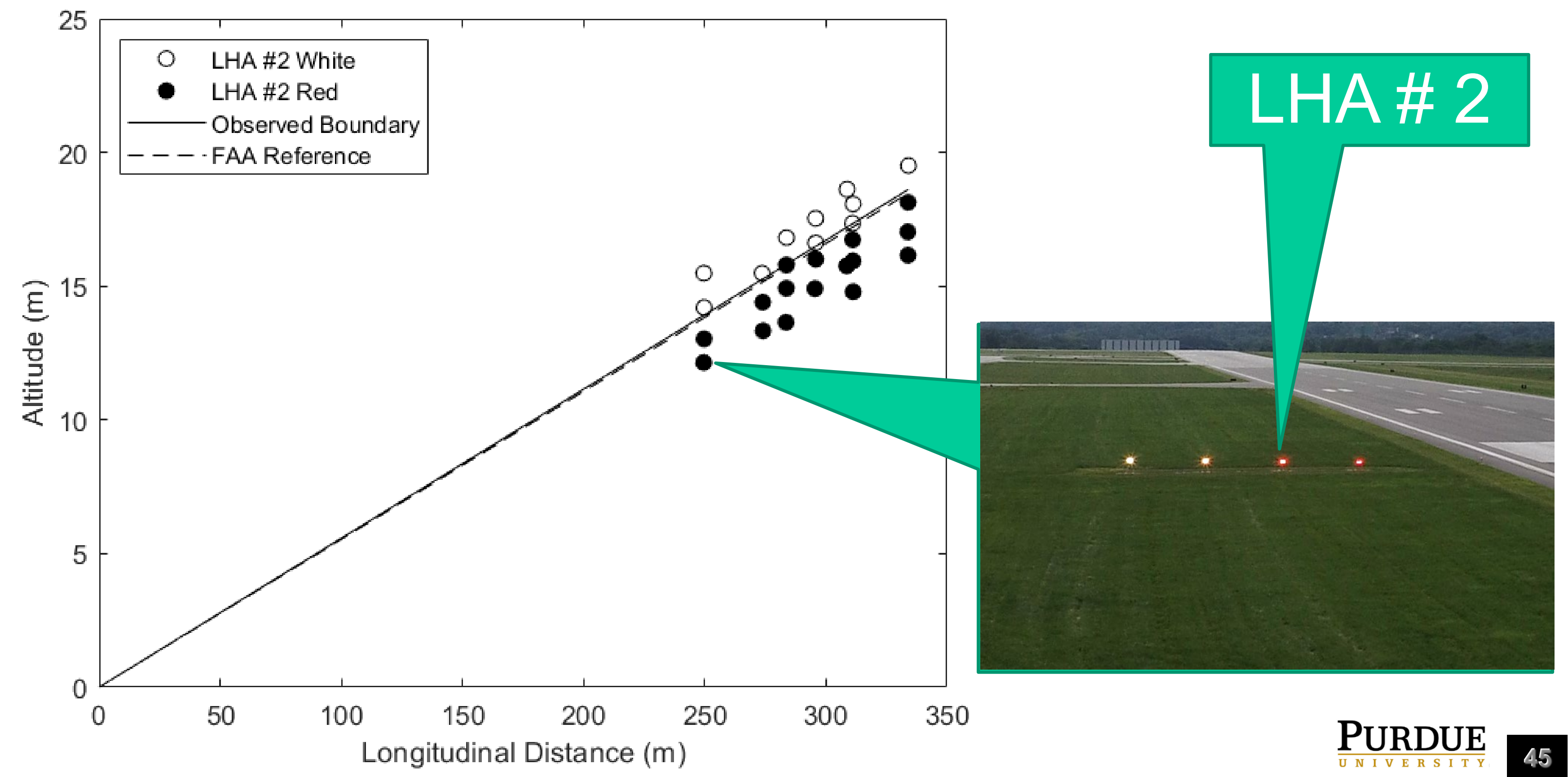

PURDUE 


\section{Estimated Transition Angle or PAPI lights (4)}

Boundary betweer 0 and 1 red lights (LHA \#1)
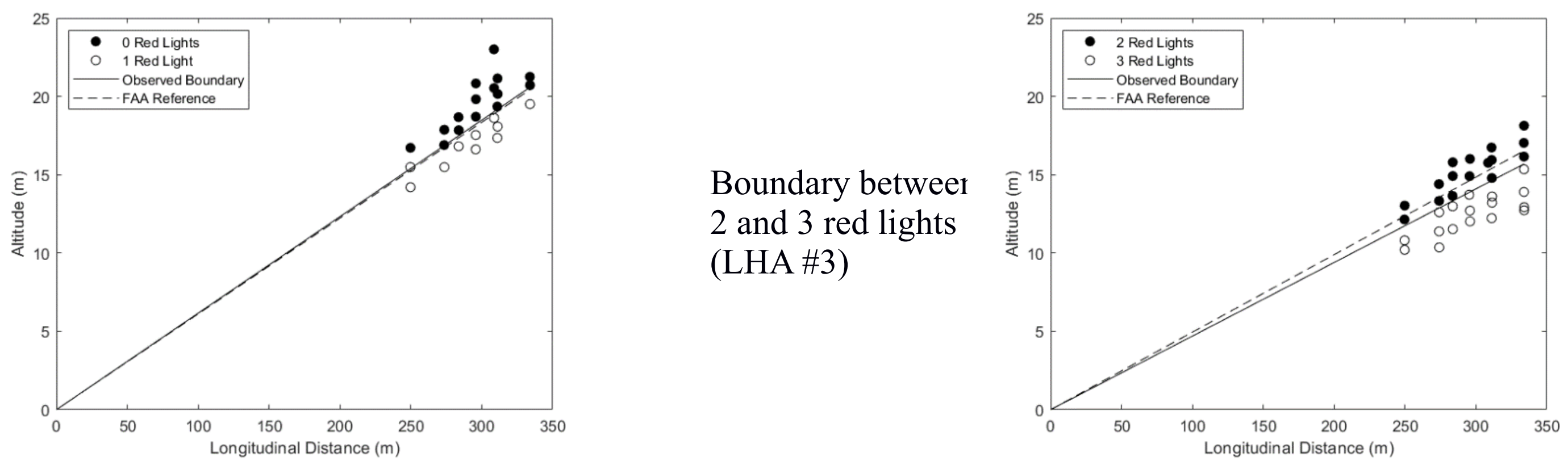

Boundary betweer 1 and 2 red lights

(LHA \#2)

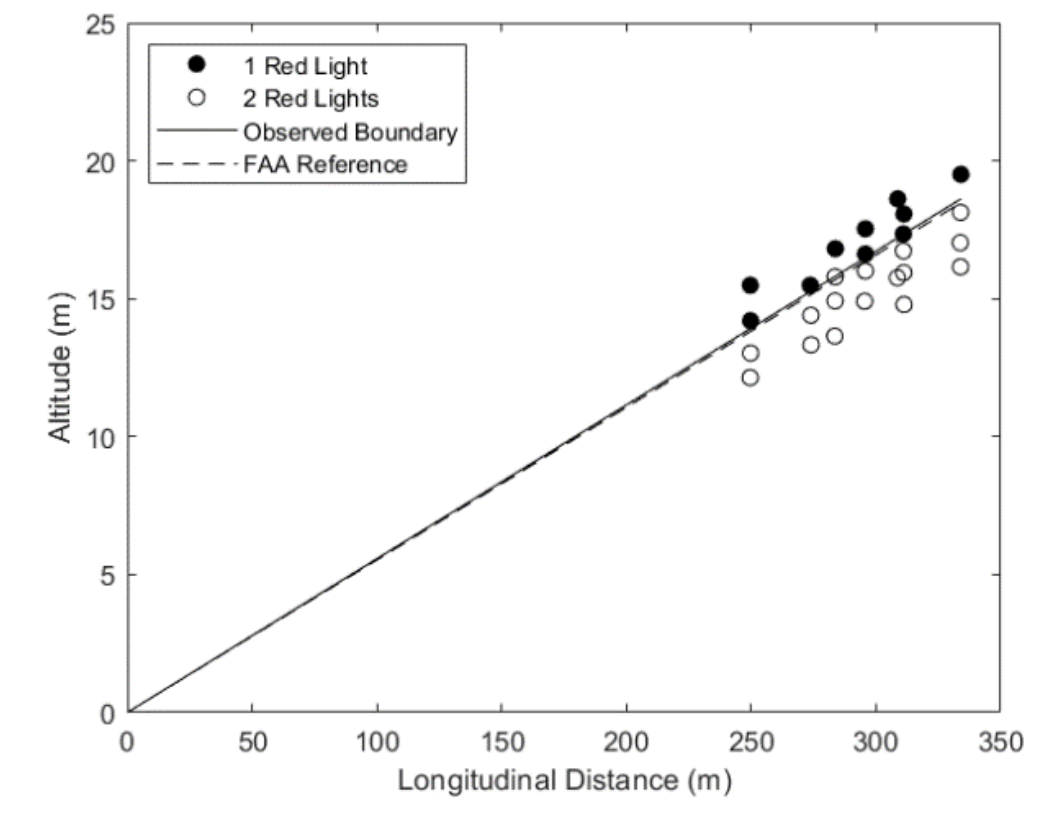

Boundary betweer 3 and 4 red lights (LHA \#4)

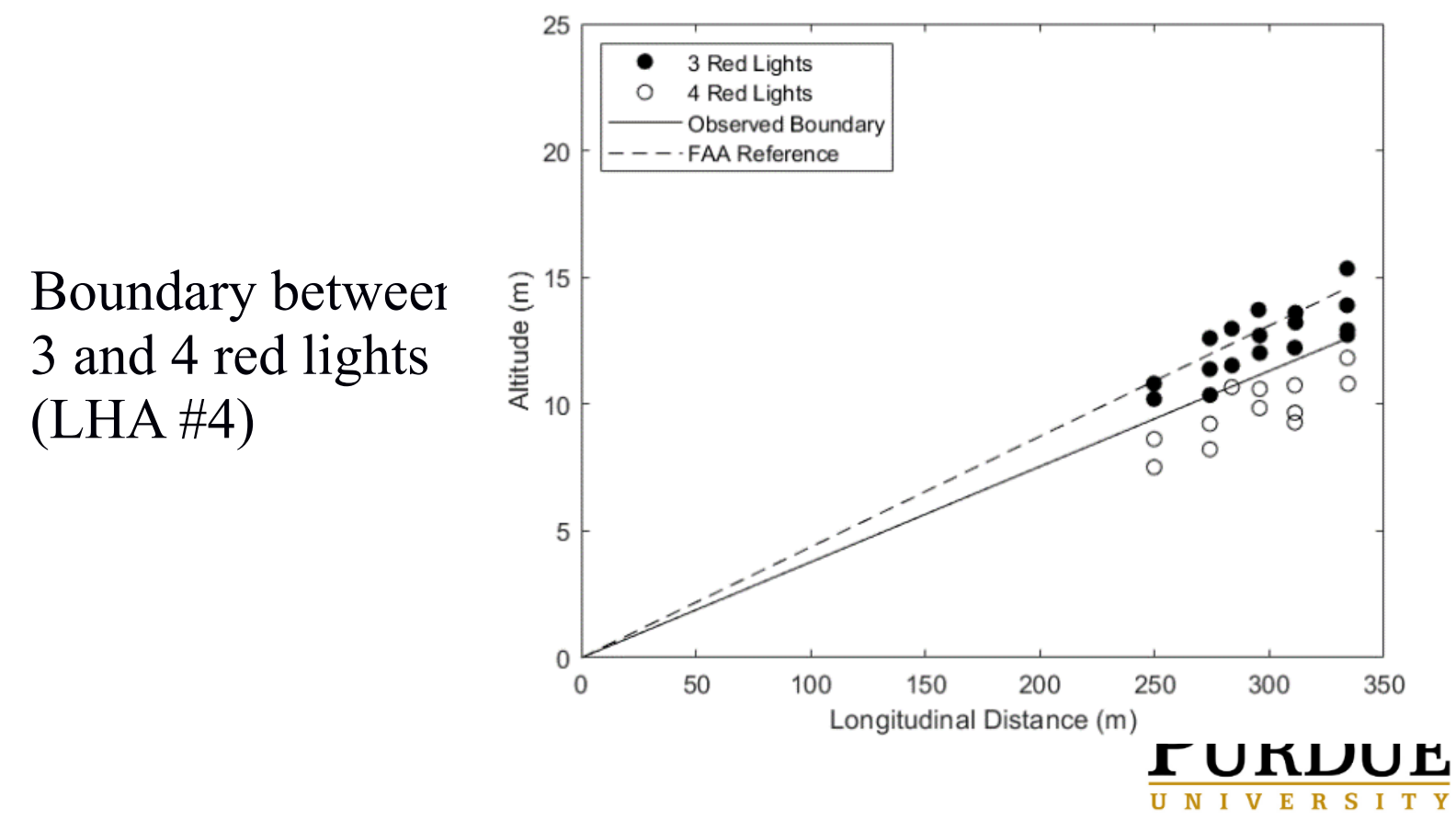

Boundary betwee 2 and 3 red lights (LHA \#3) 


\section{Estimated Transifion Angle for PAPI Lights}

- Small p-value: confidence that the model is effectively classifying the transition angle

- The transitions from 0 to 1 red PAPI lights and 1 to 2 red PAPI lights (correspond to LHA \#1 and LHA \#2) are within the allowable tolerance

- The transitions from 2 to 3 red PAPI lights and 3 to 4 red PAPI lights (correspond to LHA \#3 and LHA \#4) are outside of the allowable deviations $\rightarrow$ adjusted according to the manufacturer guidelines and FAA Advisory Circular 150/5340-26C

Comparison of logit model estimate of red/white transition with expected transition glide slope

\begin{tabular}{|c|c|c|c|c|c|c|c|c|c|}
\hline LHA & $\#$ Obs & A & $\begin{array}{c}\mathrm{p} \text {-value } \\
\text { of } \mathrm{A}\end{array}$ & B & $\begin{array}{c}\mathrm{p} \text {-value } \\
\text { of } B\end{array}$ & $\begin{array}{c}\text { UAS } \\
\text { Calculated } \\
\text { Glide Slope } \\
\text { (deg) }\end{array}$ & $\begin{array}{l}\text { Expected } \\
\text { Glide } \\
\text { Slope } \\
\text { (deg) }\end{array}$ & $\begin{array}{c}\text { Difference } \\
\left({ }^{\circ}\right)\end{array}$ & $\begin{array}{l}\text { Difference } \\
\text { (min) }\end{array}$ \\
\hline$\# 1$ & 25 & 2947.7 & 0.029 & -181.7 & 0.030 & 3.526 & 3.500 & 0.026 & 1.584 \\
\hline$\# 2$ & 26 & 86386.0 & 0.000 & -4815.1 & 0.000 & 3.190 & 3.167 & 0.024 & 1.418 \\
\hline$\# 3$ & 33 & 71714.0 & 0.000 & -3369.8 & 0.000 & 2.690 & 2.833 & -0.143 & -8.582 \\
\hline$\# 4$ & 29 & 90100.0 & 0.000 & -3397.4 & 0.000 & 2.160 & 2.500 & -0.341 & -20.430 \\
\hline
\end{tabular}

Allowable tolerance specified in FAA Order JO 6850.2B: 0.083 (5 arc-min) 


\section{Independent Check of Tola Stations Locations}

- The slope distances from PAPI light LHA \#1 to UAS locations and the slope angles were calculated using both Topcon and Trimble measurements

\begin{tabular}{|c|c|c|c|}
\hline Measurement & Mean & Standard Deviation & RMSE \\
\hline Slope Distance & $0.060 \mathrm{~m}$ & $0.060 \mathrm{~m}$ & $0.085 \mathrm{~m}$ \\
\hline Alpha Angle & $0.0058^{\circ}$ & $0.0219^{\circ}$ & $0.0225^{\circ}$ \\
\hline
\end{tabular}

- The transition angles estimated using the Trimble data are $3.534^{\circ}, 3.172^{\circ}, 2.676^{\circ}$ and $2.155^{\circ}$, for LHA \#1, LHA \#2, LHA \#3 and LHA \#4, respectively $\rightarrow$ the differences are within 1 arc-min when compared with the Topcon estimates

- These results suggest that the accuracy of the UAS location and glide path angle are $\pm 0.0085 \mathrm{~m}$ and $\pm 0.0225^{\circ}$ (1.35 arc-min), respectively.

Smaller error then in how pilots sit in cockpit or adjust their seat 


\section{Topics (7)}

1. Research Team

2. Problem Statement

PAPI (PI, P2, P3)

APAPI (AP)

3. PAPI Light Concept

4. PAPI Light Images from Left Seat of Cessna 170

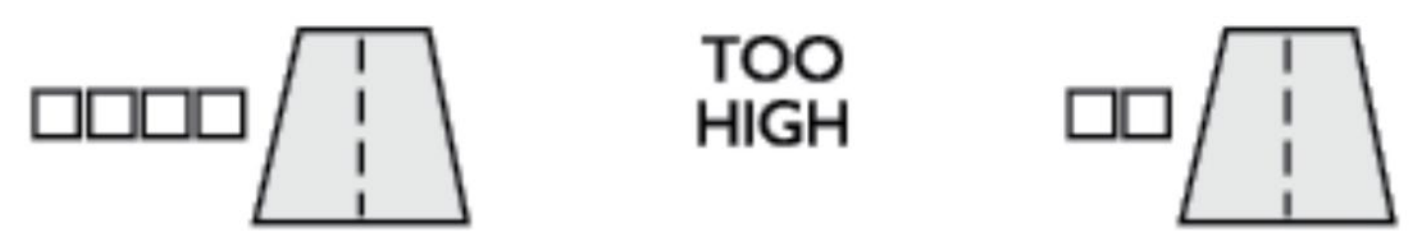

5. Surveying Procedures

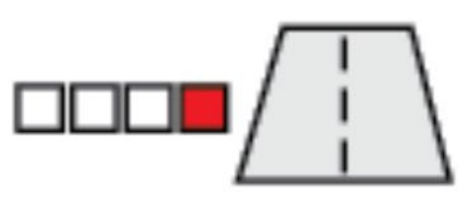

SLIGHTLY $\mathrm{HIGH}$

6. PAPI Light Images from UAS

7. Glideslope Angle Estimate

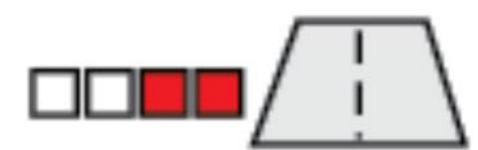

ON CORRECT APPROACH PATH

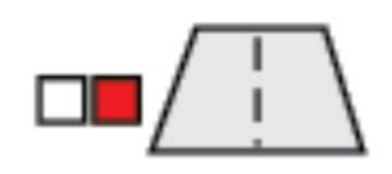

8. Conclusion and Ongoing Implementation Activities

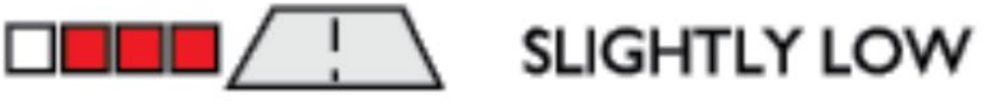

$\square \square \square$ TOO LOW

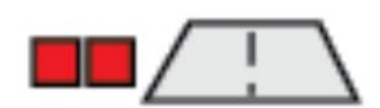




\section{Ongoing Implementation A tvittes}

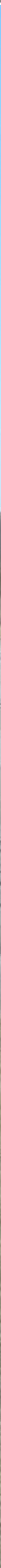




\section{Ongoing Implementation Ac vities (2)}

- This also works well with 2 light APAP (marginally quicker)

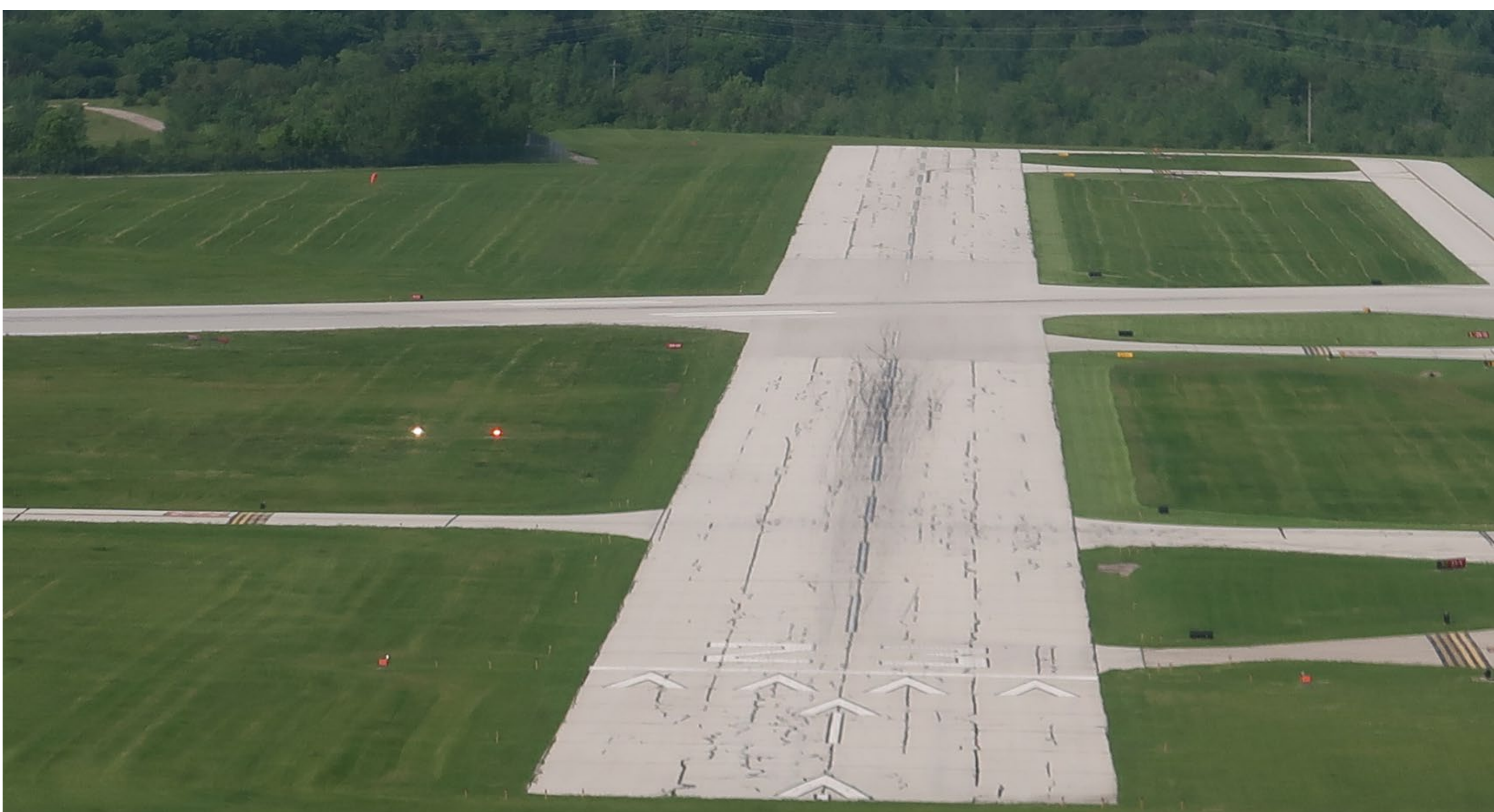


- UAS is used to measure the glide slope angle of a four-box PAPI system transitions from white to red to assess compliance with FAA Order JO 6850.2B

- The estimated transition angles of LHA \#1 and LHA \#2 are $3.53^{\circ}$ and $3.19^{\circ}$, well within the 5 arc-min tolerance defined in FAA Order JO 6850.2B. The estimated transition angles of LHA \#3 and LHA \#4 are $2.69^{\circ}$ and $2.16^{\circ}$, both outside of the tolerance

- These findings suggest that PAPI light glidepath angles can be quickly and cost effectively validated with low cost UAS's and commonly used surveying equipment

- This activity was done in partnership with the FAA and operations continued on runway 5/23 during missions.

- With proper preparation, inspection can be done during a single 20 minute UAS flight..

- Opportunities for Further work

- Instead of a \$1200 UAS and Surveying equipment, deploy a \$12,000 UAS with integrated IMU and higher fidelity GPS so that UAS position is recorded with a couple of $\mathrm{cm}$ accuracy. 


\section{Peru Airport APAPI Survey}

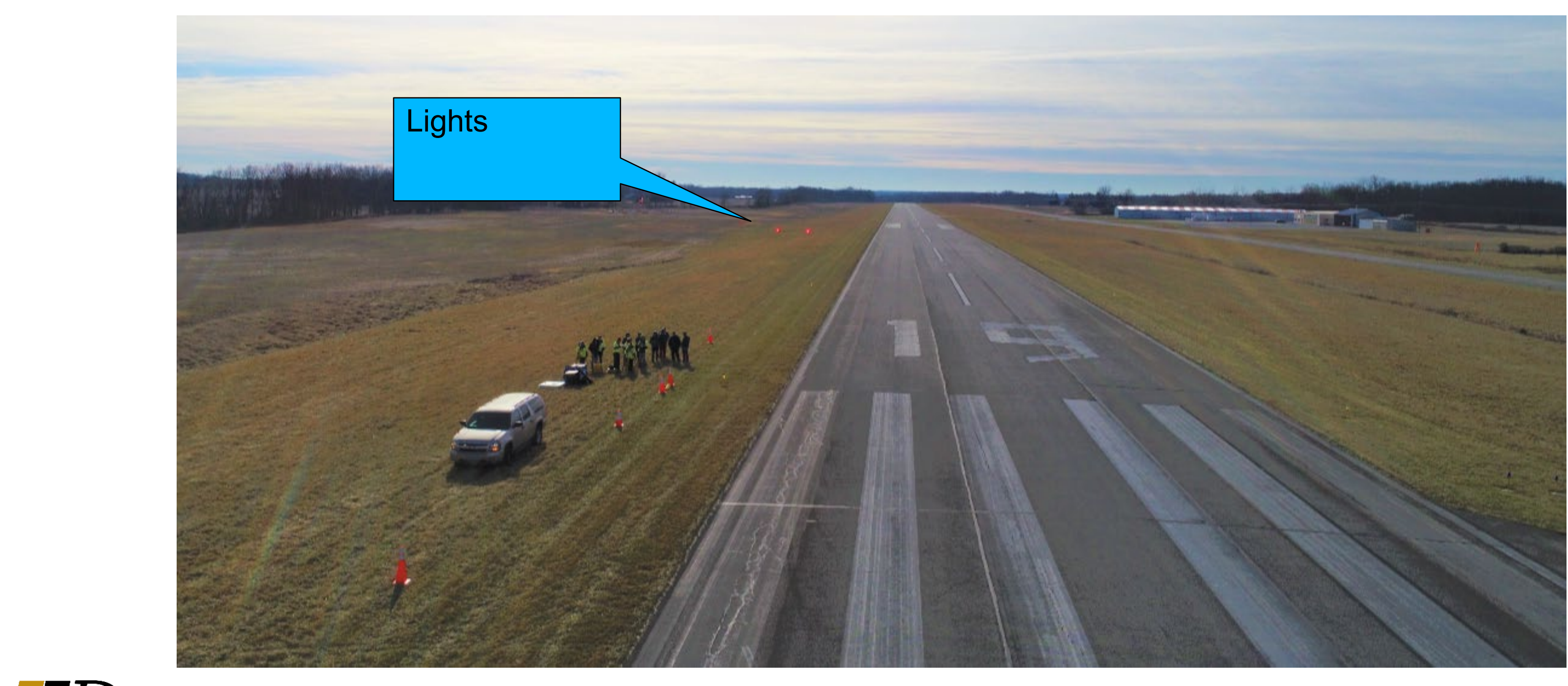




\section{Backsite}

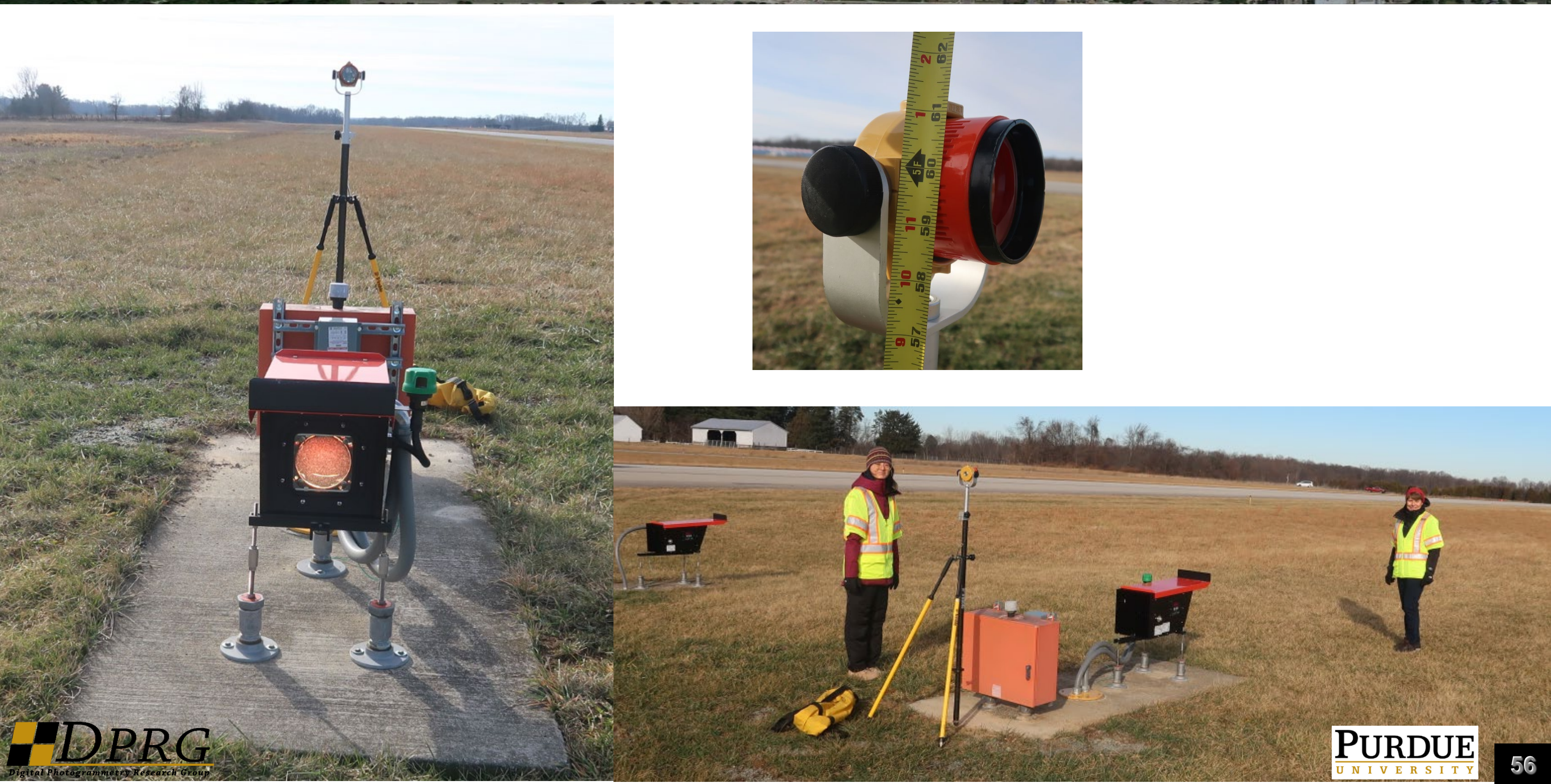




\section{UAS Measurement Location}

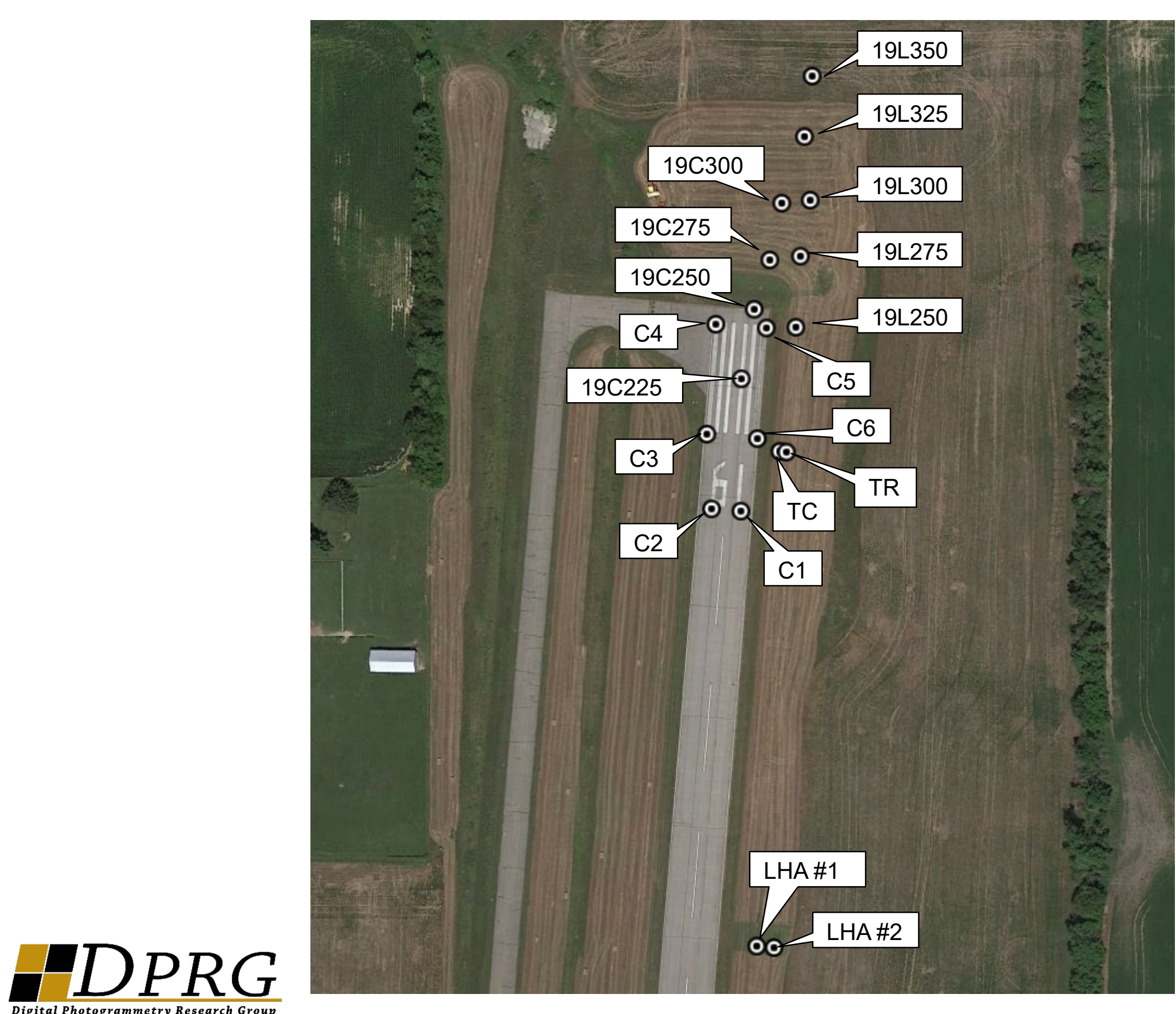

- LHA \#1, LHA \#2: the PAPI light units

- 19L350, 19L325, 19L300, 19L275, 19L250, 19C300, 19C275, 19C250, and 19C225: the locations where the UAS flew vertical profiles

- TC and TR: the locations of the Topcon and Trimble total stations

- C1, C2, C3, C4, C5 and C6: six control points which were surveyed using both total stations and RTK-GNSS 


\section{Sample Photo from Phanto (1 red, 1 white)}

1 Red, 1 White 


\section{ICAO Standard for APAP C of Angles}

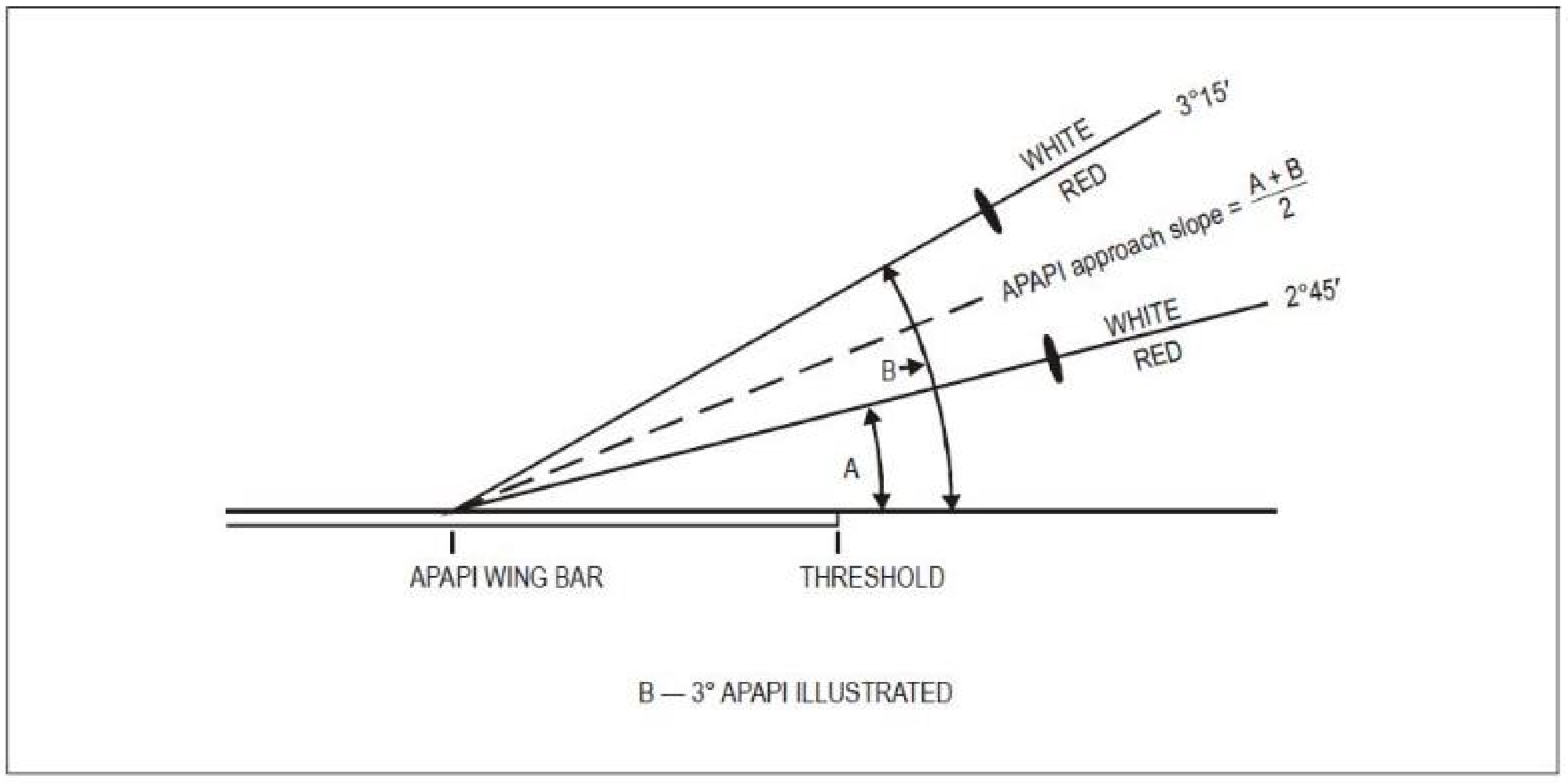

Figure 5-20. Light beams and angle of elevation setting of PAPI and APAPI 


\section{APAPI Light Confiğuration?}

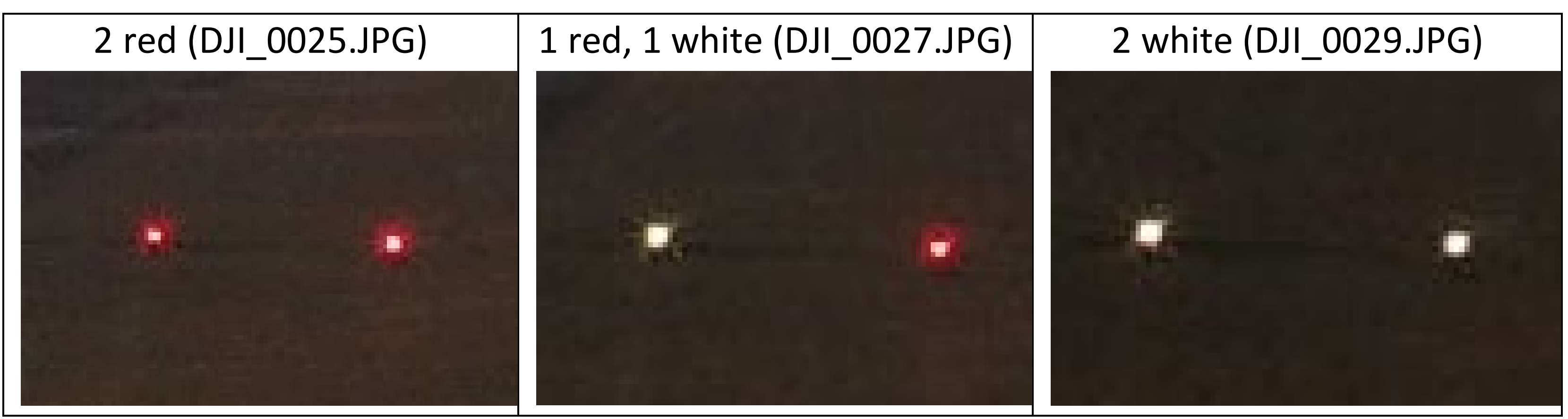




\section{Spatial Reference for Eagh AS Image (2)}

- Georeference total station measurements to UTM coordinate system using ground control points

- Decompose the total station angle and distance measurements into longitudinal (parallel to the runway) and lateral components

- Calculate glide slope and glide path angle

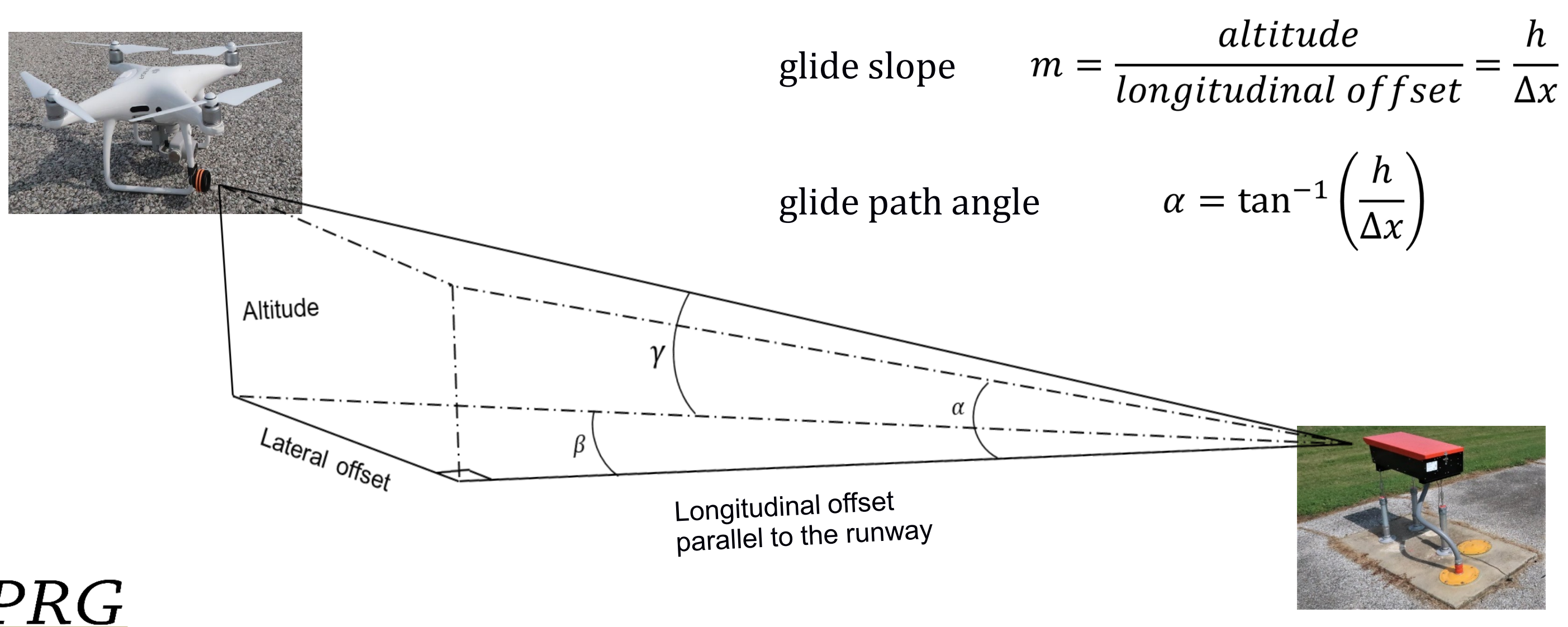




\section{LHA \#2 Results}

Observed

Angle: $2.826^{\circ}$

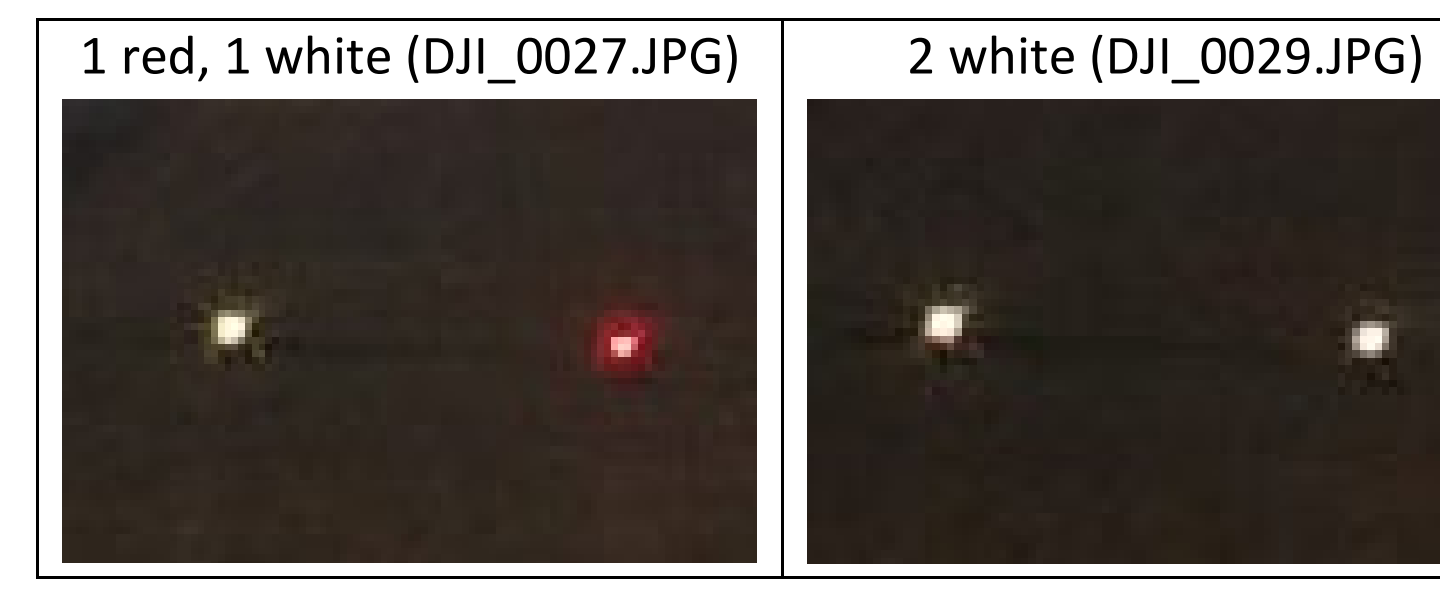

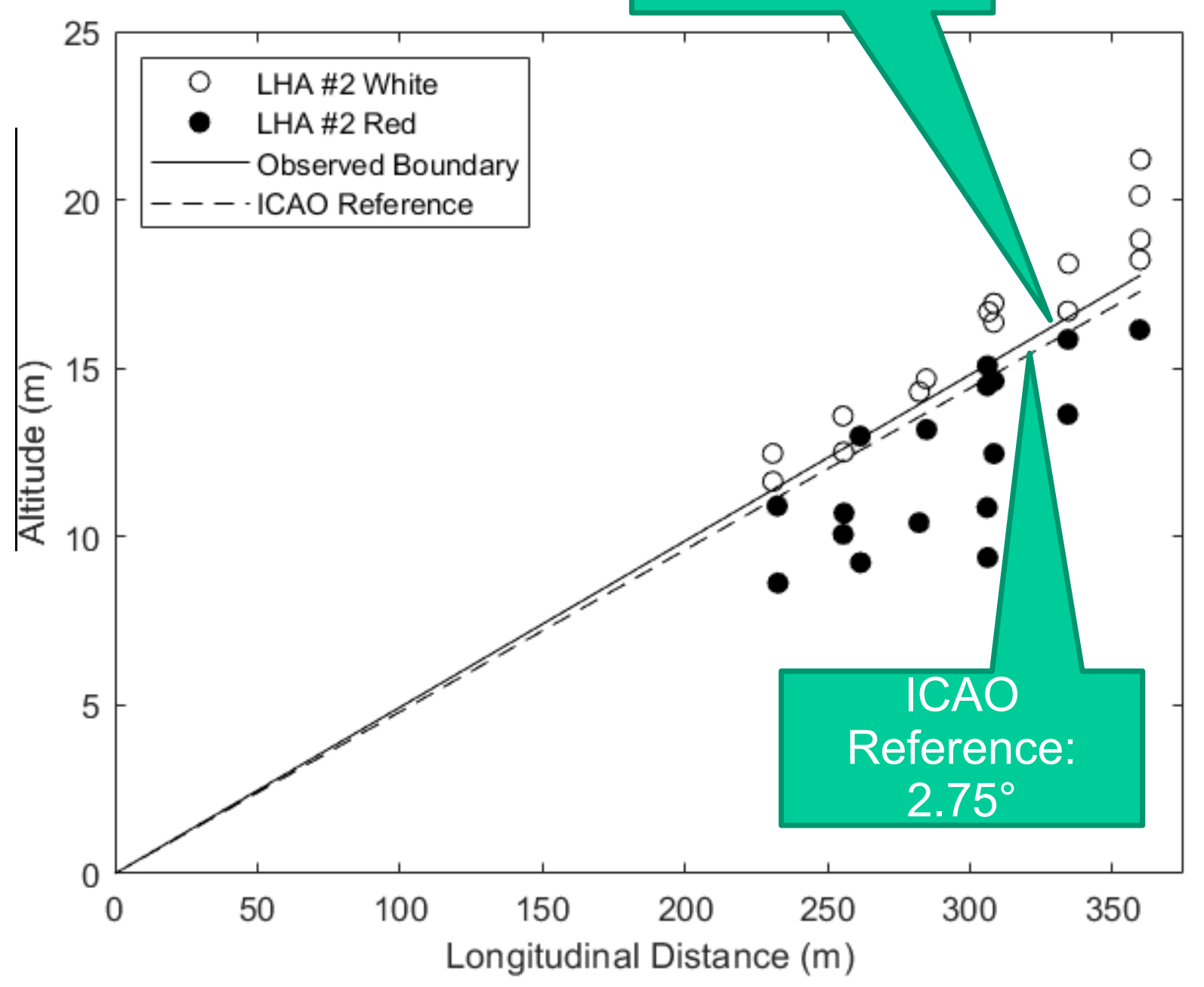

DPRG Allowable tolerance specified in FAA Order JO 6850.2B: 0.083 (5 arc-min) $+1$ 


\section{LHA \#1 Results}

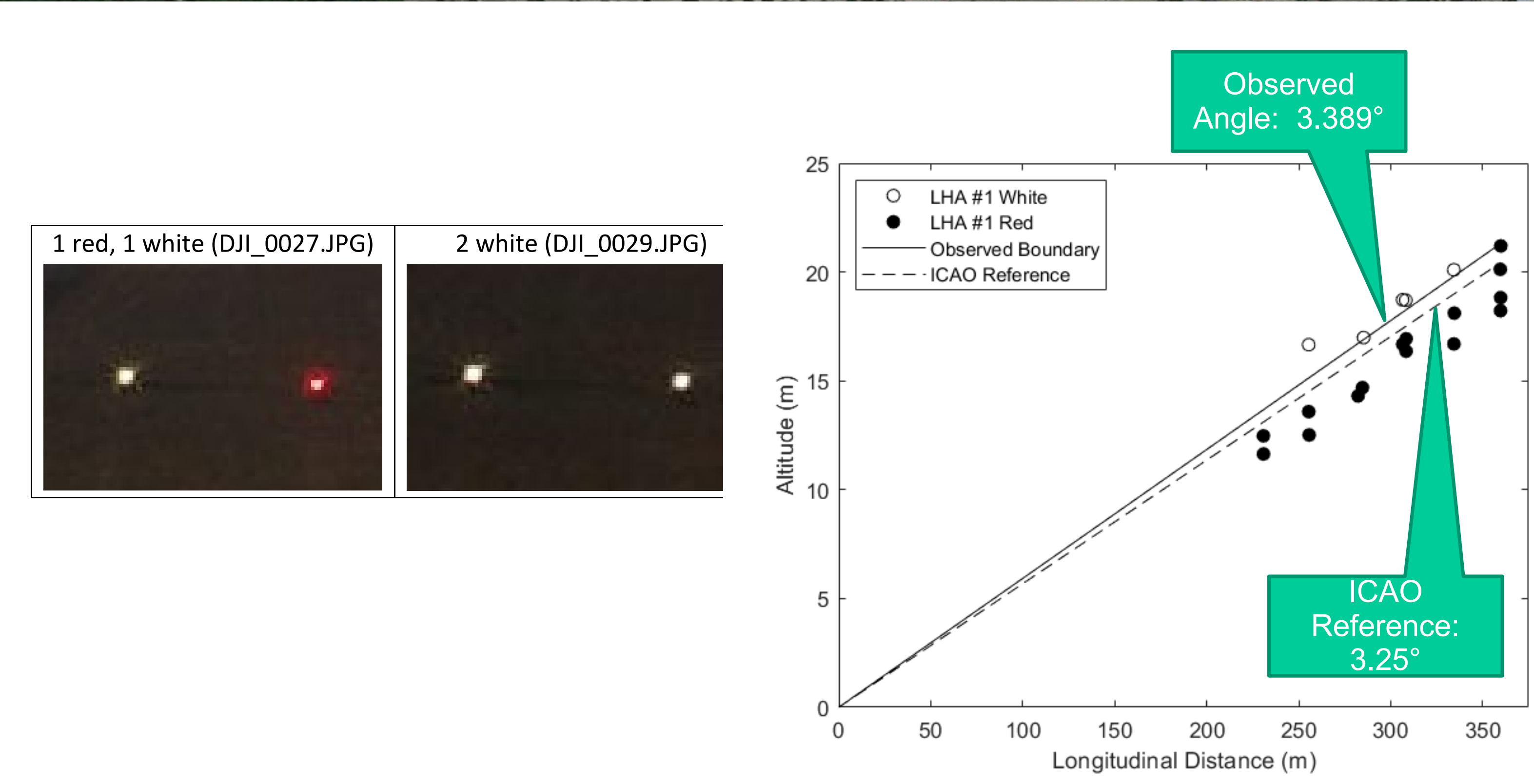




\section{Contact Information}

Ayman Habib: ahabib@purdue.edu

Darcy Bullock: darcy@purdue.edu https://twitter.com/darcybullock

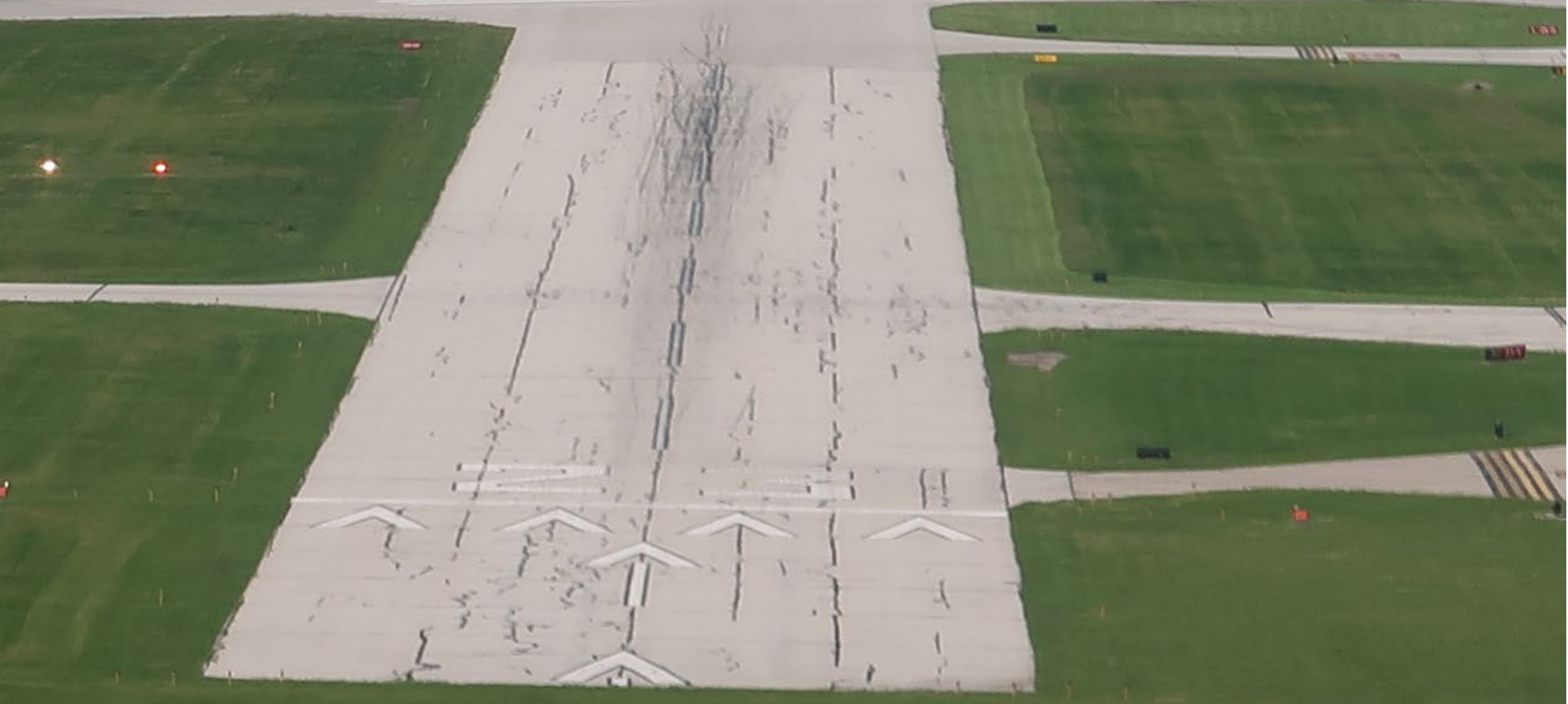

